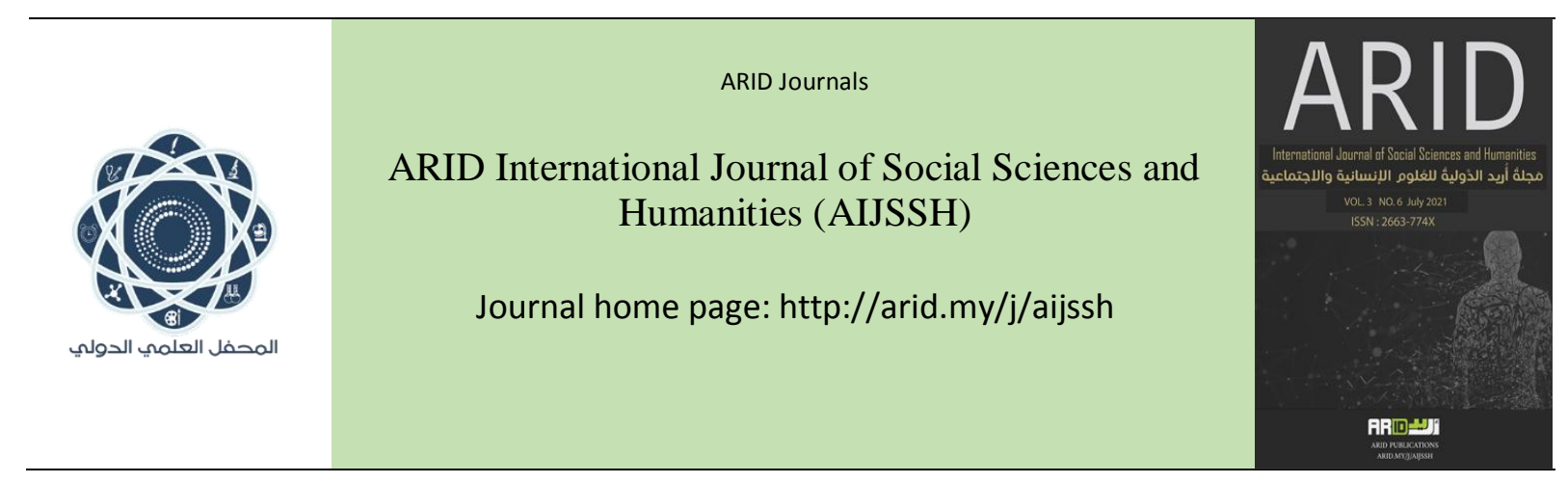

$$
\begin{aligned}
& \text { مَجلةُ أُريد الدَّوليةُ للعُلومِ الإنسانية والإجتماعية } \\
& \text { المجلد الثالث ،العدد السادس، تموز } 2021 \text { م }
\end{aligned}
$$

\title{
Dimensions of Civil Responsibility in Egyptian Universities (A comparative study on the Universities of Alexandria and Pharos)
}

\author{
أبعاد المسؤولية المدنية في الجامعات المصرية

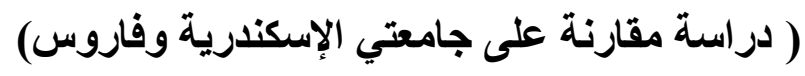 \\ مرفت مسعود جاب الله علي قطوش \\ علم الاجتماع السياسي- جامعة عين شمس-جمهورية مصر العربية
}




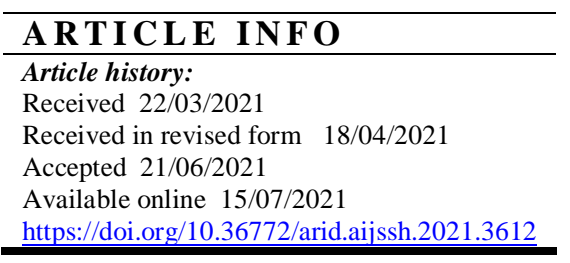

\section{ABSTRACT \\ "The Dimensions of Civil Responsibility in Egyptian Universities"}

A comparative study on the universities of Alexandria and Pharos

\section{Research goal}

Knowing the "dimensions of civil responsibility of the two universities", knowing the obstacles facing the community service sector and trying to develop a vision; to activate the role of the two universities towards the university's civil responsibility, and how to benefit from it in developing universities.

The research relied on the descriptive and analytical approach and the use of the sample social survey method in collecting data for the two universities in question, and using the interview guide with the agents of the scientific and theoretical colleges (trade and pharmacy) in the two universities for community service and environmental development, in addition to the vice presidents of the two universities for community service and environmental development, and members of the faculty, The research focused on analyzing ready-made data, analyzing community service activities and developing the environment.

\section{The research reached a number of results, the most important of which are}

-The results of the current research confirmed that there is a difference in civil liability among students of theoretical colleges from students of practical colleges, in terms of interest in democracy (humanities) is not equal to the contents of the materials that you take, which means that there are other factors responsible for a service that do not benefit from these topics, these factors It can be the teaching methods and the educational environment.

-The results also revealed a relationship between community service and civic responsibility, and civil responsibility emerged through the relationships between students, the educational staff and professors, individually or collectively, and participation in volunteer work such as seminars and various community activities to serve the community.

-The results showed the achievement of democracy for the two universities through effective interest in the community activities carried out by students, and showed a clear difference between citizenship of the two universities in the available resources.

-The results of the research showed the clear difference between the two universities in the dimension of investigation and deliberation, as Pharos University occupies the highest position in the application of this aspect.

Keywords:( Civil Responsibility, Community Service, Dimensions, Sustainable Development, Law culture). 


\section{الملخص}

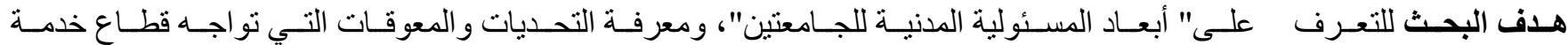

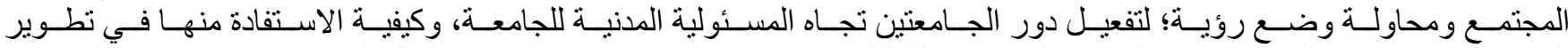

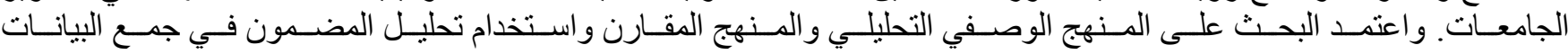

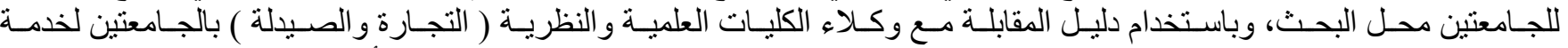

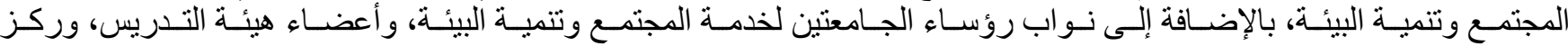
البحث على تحليل البيانات الجاهزة، وتحلينة الإنيل أنشطة خدمة المجتمع وتنمية البيئة.

\section{توصل البحث إلى عدد من النتائج أهمها:}

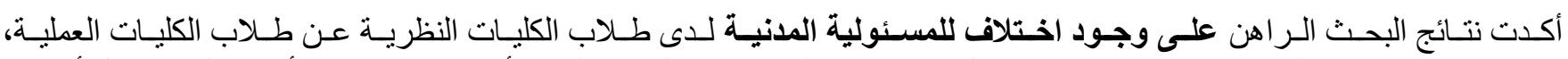

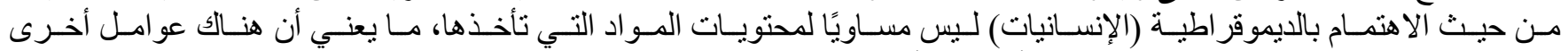
مسؤولة من هذه المو اضيع، هذه العو امل يمكن أن تكون أساليب التدريس و البيئة التعليمية.

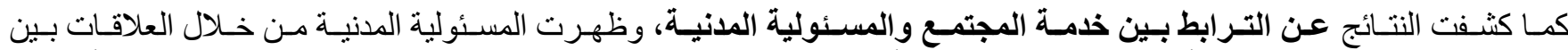

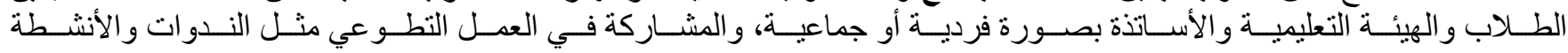
المجتمعية المتنو عة لخدمة المهربة المجنمع.

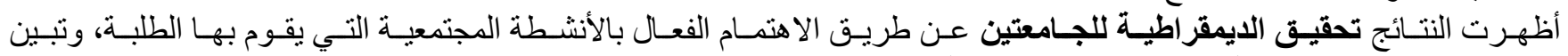

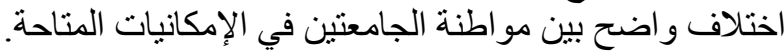

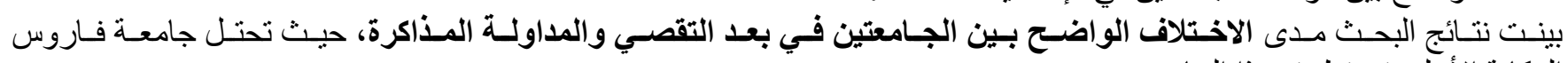
المكانة الأعلى في تطبيق هذا الجانب. الكلمات المفتاحية

( المسئولية المدنية، خدمة المجتمع، الأبعاد، التنمية المستدامة، نقافة القانون ) 
ظهرت أهمية البحث في التركيز على الجامعات كونها المركز الذي يشع الحضـار ات في أي مجتمع، فدور الجامعة مهم وشـامل ومميز يتضح في ثلاث وظائف رئيسية كالتالي التعليم والبحث العلمي وخدمة المجتمع لأن الغايـة الرئيسية من نشـأة الجامعات هي إعداد الأجيال المتعاقبـة مـن أبنـاء المجتمعـات للاضطلاع بمسئولياتهم كمواطنين بالإضـافة إلى أنـه لا بمكن أن تؤدي تلك الجامعـات دور هـا الإيجابي في التغيير الاجتمـاعي، بدون تحقيق التفاعل بينها وبين المجتمعات: هو الضرورة القسوة إلى إعداد بنـاء وتتميـة المواطنين وتو عيتهم من خلال التعليم: الذي يسهم في تنمية قدرات الطلاب و إعدادهم للعمل.

ويتضح ذلك من خلال تحصيل المعلومات بما يسهم في إعداد رأس المال البشري، وخلمـة المجتمع. تقوم الجامعات بدور أساسي في تتميـة المجتمع مـن خـلال تتميـة رأس المـال البشرى باعتبار هـا أهم مقومـات تنميـة البحث العلمي: وتوضيح الدور الكبير في تقدم المجتمعات.[1] ومن هذا المنطلق تسعى الباحثة لتناول التر ابط والصلة بين المسئولية المدنية لجامعات، ومعرفة الدور الذي تقوم بـه من خلال وجهة نظر وكلاء ونواب الجامعات وفقًا للتغير ات التي طر أت على وظائف الجامعـات، وظهور مصطلحات متعدّدة تدل على الأبعاد المدنية للجامعات على سبيل المثال لا الحصر: المسئولية الاجتماعية، المسئولية المدنية، الالتزام والتعليم المدني، المو اطنة، خدمـة المجتمع...إلخ. و الملفت أن هذه العبار ات قد نجدها أحيانًا تبادلية وتشكل أهية لدور الجامعة الحديث وهو المسئولية المدنيـة، مبررًا لهذا البحث الحالي. بالإضـافة إلى الأبعاد المدنية الأخرى التي يركز عليها البحث مثثل: ( الديمقر اطية، بيداغوجيا التقصي و المداولة، ثقافة القانون، الحريـة الأكاديمية). و عليه فإن هناك سببان يدعوان إلى التفكير بدور مـا تسميه" بالمسئولية المدنيـة للجامعات ( الإسكندرية، وفاروس)، ودور ها في تنمية المجتمع، بالإضـافة إلى دوري التعليم والبحث العلمي، والتدريس. وقد ظهرت النزعات المختلفة محولى الاهتمام بالتعليم الجامعي و التي تتضح فيما يلي:

أولًا: النزعة الاقتصادية النيولييرالية التي تجتاح مؤسسات لتعليم العالي عبر العالم: وتعطي الأولية للتنافس ولمتطلبات السوق، وقد ظهرت كتابـات شـيدة النقد لهذا النمـوذج منـذ التسعينات لأنـه يضـع المسـائل الاجتماعيـة والسياسـية والأخلاقيـة جانبـا. ويهمـش تعليم الإنسـانيات، ويضـع الأسـاتذة تحت رحمـة التعاقد قصبر المدى، وقد تطور النقد إلى نزعة مضـادة عبر عنها " إعلان الرؤسـاء حول المسئولية المدنية للتعليم العالي" 1999، ثم إعلان تالوار حول " الأدوار المدنية والمسؤولية الاجتماعية للتعليم العـالي. خـلال السنوات الأخيرة زاد اهتمـام البـاحثين وصناع السياسـة نظرا لأهمية الجامعات في المجتمع بجانب الوظائف التقليديـة، ويستتد هذا الاهتمام إلى الفو ائد المتنو عة المتر تبة على مشاركة الجامعات في المجتمع من قبل تنميـة الوعي والاحسـاس بالمسئولية المجتمعية والمدنية، وتحسين جودة العملية التعليمية، وتوجيه البحث العلمي، بما يفيد المجتمع. وضمان الجودة التي تتصب على كل مهام وأنشطة التعليم: التدريس، 
ثانيا: قد برزت منذ التسعينيات من القرن الماضي حركة عالمية تدعو إلى إعادة تقوية الطابع المدني أو الايمقراطي: وظهرت ملامح هذه الحركة في التعليم العالي، ثم تو الت الدعوات و الاهتمامات العالمية لاحقا بهذا الجانب، وأصبحت الجامعات المشاركة مدنيا ومجتمعيا ظاهرة عالمية تصف مؤسسات التعليم العالي التي اختارت أن تكون لاعبا نشطا في حياة مجتمعاتها.3] بينما اتجهت الجامعات المصرية حديثًا بالا هتمام بالمسئولية المدنيـة للجامعات. و أصبحت قضية المسئولية المدنية محل اهتمام العديد من تخصصسات العلوم الاجتماعية و الإنسـانية مثثل (علم الاجتمـاع السياسـي، وعلم الاجتمـاع التربوي، وعلم اجتمـاع التنميـة)، فالمسئولية المدنيـة أصبحت محل اهتمـام الجامعات العربية، وخاصة جامعات الدول المتقدة نظرًا لأهميتها في تطوير وتتمية مجتمعاتها. ومما سبق دعي الباحثة للاهتمام بأبعاد المسئولية المدنية للجامعتين (الإسكندرية وفاروس) بـالتركيز على مؤشرات المسئولية المدنية؛ وذلك لأنها تكون جزء من متطلبات الجامعة المفروضة، وفي بعض الأحيان تتم بمبادرات تطو عية من الأساتذة والطلاب بصورة فرديـة. وفقًا لاستر اتيجية التنمية المستدامة رؤية مصر 2030 التي تضمنت تفعيل مبدأ الثر اكة المجتمعية بين الدولة والقطاع الخاص والجامعات في دعم المعرفة والبحث العلمي و الابتكار 2030 ولحظت الباحثة مما سبق وجود تحول واضح للمسئولية الاجتماعية للجامعات وحلت مكانها المسئولية المدنية من أعداد وتتميـة رأس المـال البشـري إلى تعزيـز رأس المـال الاجتمـاعي المتمثل في تعزيـز العلاقـات الاجتماعيـة، وتنميـة رأس المـال البشـري و المعرفي لدى طلاب الجامعات و اكتساب بعض المهار ات اللازمـة للعمل في تخصصـاتهم، دون الاهتمام بالتدريس و المتمتلة في مدى ضرورة الدفاع عن حقوق المواطنة وحقوق الإنسان.

ينطلق البحث الراهن من التساؤل الرئيسي الآتي " كيف تساهم أبعاد المسئولية المدنية للجامعات المصرية في المجتمع.؟" ويتضمن موضوع البحث خمس محاور أساسية يتناول المحور الأول: المسئولية المدنية للجامعات المصرية ( الإسكندرية وفاروس)، ويعرض المحور الثاني: الدراسات السابقة الخاصة المسئولية المدنية للجامعات ( الإسكندرية وفاروس ) و مناقتشتها بينما يناقش المحور الثالث: التحديات و المعوقات التي تواجه تطبيق أبعاد المسئولية المدنية والدور المدني في الجامعات المصرية أمسا المحور الرابع: يتنـاول التصور المقترح للمسئولية المدنية للجامعات المصرية ودورها في تنمية المجتمع وخدمته ويناقش المحور الخامس: نتائج البحث. المحور الأول: المسئولية المدنية للجامعات المصرية ( الإسكندرية وفاروس). ويمكن توضيح المسئولية المدنية للجامعات المصرية من خلال التصور المقترح للاتجاه النظري والمنهجي للبحث كالتالي: أولا: مشكلة البحث تعد المسئولية المدنية وأبعادها مرجعية نظرية للخلال تتمية فهي تعتبر أحد أركان الثالوث المتداول في أدبيات التعليم العالي وفي رسالات ورؤى العديد من الجامعات، وبما أن المسئولية المدنية تعتبر موضوع مهم؛ لأنها تضم مصطلحات متعدّدة فالمسئولية جزء 
فردية. فالجامعة لا يمكن أن تؤدي دور ها الإيجابي في التغيير الاجتماعي، بدون تحقيق التفاعل بينها وبين المجتمع من خلال التعليم الذى يسهم في تتمية قدر ات الطلاب و إعدادهم للعمل وتحصيل المعلومات بما يسهم في إعداد رأس المال البشري، وخدمة المجتمع. فالجامعات تقوم بدور أساسي في تتمية المجتمع ويمكن القول أن " المسئولية المدنية للجامعات" ترتكز على مدى قيامها بتو عية وتثقيف الطلاب مدنيا بقضـايا ومفاهيم مهـة كالمسئولية المدنية و المو اطنة وخدمة المجتمع التوعية وتنفيذ الأنشطة المختلفة والبر امج المجتمية و المقررات الدراسية بالجامعات و إنما الدور المدني للجامعات الذي يفترض أن تقوم به هو توعية وتثقيف الطلاب. وبناءةً على ما سبق يتتاول هذا البحث أبعاد المسئولية المدنية للجامعتين ( الإسكندرية وفاروس)، ومعرفة الدور المدني للجامعات، وخدمة المجتمع، والمو اطنة، ومدى تفعليها من وجهة نظر وكلاء

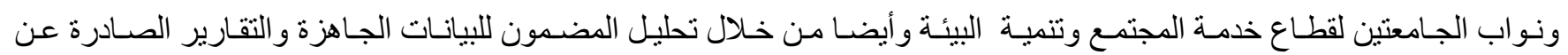
الجامعتين محل البحث لشئون خدمة المجتمع وتتمية البيئة، ومعرفة بروتكو لات الثر اكة المجتمعية والأنشطة مع الجهات المختلفة.

\section{ثانيًا أهمية البحث}

يعالج البحث موضوعًا حيويًا وهو الدور المدني للجامعات المصرية ( المسئولية المدنية للجامعات)، فالمسئولية المدنيـة للجامعـة من

أهم القضايا التي تفرض نفسها عند معالجة مشرو عات إصلاحها، وخاصة النظام التعليمي بالجامعات المصرية.

بينمـا تتضـح الأهميـة النظريـة للبحث في تنـاول أبعـاد الدور المدني للجـامعتين (الإسكندرية، وفاروس). والدور المدني للجامعتين للوقوف على إنجاز ات قطاع خدمة المجتمع وتتمية البيئة، ونشر التقارير ومحاضر الاجتماع الخاص.

ثُالثاً: أهداف البحث وتساؤلاته تتمثل أهداف البحث في

1. التعرف على أبعاد المسئولية المدنية للجامعتين. ( الإسكندرية وفاروس)

2. ر رصد دور الجامعات في خدمة المجتمع وتتميته ( الإسكندرية وفاروس)

3. رصد التحديات و المعوقات التي تو اجه الجامعتين في تفعيل وتطبيق الدور المدني للجامعات المصرية

4. التعرف على آليات تفعيل المسئولية المدنية للجامعات المصرية ( الإسكندرية وفاروس) 


\section{وتتمثل تساؤلات البحث فيما يلي:}

يتضح التساؤل الرئيسي في الآتي " كيف تساهم أبعاد المسئولية المدنية للجامعات المصرية في المجتمع.؟ وينبثق عنه الاسئلة الفرعية

ما أبعاد المسئولية المدنية للجامعات ( الإسكندرية وفاروس )؟

ما دور الجامعة في خدمة المجتمع وتتمية البيئة؟

ما التحديات و المعوقات التي تواجه تطبيق الجامعتين ( الإسكندرية وفاروس ) لأبعاد المسئولية المدنية؟

ما آليات تفعيل المسئولية المدنية للجامعتين ( الإسكندرية وفاروس)؟

\section{رابعًا: الاتجاهات النظرية المفسرة للبحث}

1 - نظرية التتمية البشرية المستدامة: يعتمد البحث على نظريـة التنميـة البشرية المستدامة: فلا يمكن تفسير العلاقة بين المسئولية المدنيـة

وخدمة المجتمع بدون الاعتمـاد على نظريـة التنميـة البشرية المستدامة؛ فالتنميـة المستدامة تقر بمشـاركة جميع الجهات ذات العلاقة في اتخاذ القرار ات الجماعية. وفتح مجالات عمل جديدة، ومن هذا المنطلق يتضح ضرورة المشـاركة في مناقثـة القضـايا المختلفة، وتأثير هـا على اتخاذ القرار ات تُمكن بها سكان مجتمع، و إرساء مفاهيم التنمية المستدامة لدي خريجي الجامعات من أجل تتمية مو اردها المتاحة فهي حق الاجيـال القادمـة.[4] فهـي قائمـة على العنصـر البشـري، إذ نتطلب بـر امج التصنيع و الخطط المنتجـة المُعدة إعدادًا اجتماعِيا تلائم المجتمع، و المسئولية المدنية تعد جزء من المسئولية الاجتماعية فهما مفهومين قربيين، فالأول يعني دمه الأبعاد المدنية في الجامعات، بينما الثاني يسعي لتحقيق التنمية المستدامة بالتوفيق مع جو انب لمختلفة ايضا؛ فهناك علاقة معروفة بين الجامعات و المجتمع.5] وترتكز التنمية المستدامة على عنصرين لا يمكن الفصل بينهما أ_الحكم الرشيد. لأن التتمية المستدامة لا يمكن أن تتحقق في غياب الحكم الرشيد أو الجيد. كما أن الحكم لا يمكن أن يكون جيدا ما لم يضمن لأفراده تحقيق تنمية منواصلة ويضـع البشر في اعتباره. ومن أهم مقوماته: (1-المشاركة،2- الثقافة،3 المساءلة،4- سيادة القانون، و5-الفاعلية، 6- الرؤية الاستراتيجية). بجانب أن يتمتع القادة برؤيـة طويلـة الأجل حول متطلبات المجتمـع وأن يكون هناك فهم للتعقيدات التاريخيـة و التفافية و الاجتماعية التي تقوم عليها الرؤيـة. بـ المشـاركة: و التي تهذف لمصلحة الفرد داخل المجتمع الذي يعيش فيه.]6 


$$
2 \text { - مفاهيم البحث والتعريفات الاجرائية }
$$

\section{المسئولية المدنية والمفاهيم المرتبطة بها}

\section{المستولية المدنية: Civil Responsibility}

نتعامل مع مصطلح "المسئولية " على أنه يقتصر حصرًا على ما هو مدني. عمليًا، جعل سوليفان المسئولية المدنية، تحل فيها بصورة تبادلية محل مصطلح المسئولية الاجتماعيـة. و إلى " التطوّ ع والمشـاركة في خدمة المجتمع. [7] فـالالتزام المدني والمسئولية المدنية للجامعـات تعبر عن جانب مـن جوانب الدور المدني المتعلق بدور المتعلق بدور الجامعة في الثـأن العـام في المشـاركة في بلـورة التشريعات، و المساهمة في تطوير السياسات العامة، ومساعدة الوزارات. [8] وتعرف المسئولية لغويًا بأنها "حالة أو صفة من يسأل عن أمر تقع عليه تبعتـ"[9]، ويعرفها "معجم المصطلحات الاجتماعيـة " فيعرفها بأنها علاقة متبادلة بين طرفين أو أكثر في المجتمعات المحلية أو المجتمع العام. [10]

ويمكن تعريفها إجرائيًا: مجمو عة من البرامج والأليات التي يقوم بها الطلاب و أعضاء هيئة التدريس ( نحو المجتمع المحلي تلك البرامج و أنثطة خدمة المجتمع في إطار عقد دورات تدريبية وندوات ومؤتمرات) وتحقيق أبعادهـا: المسئولية الاجتماعيـة، الثر اكة الاجتماعية و المشاركة و المو اطنة و الديمقر اطية وخدمة المجتمع، والخدمة من أجل التعليم.

أ ـ التنمية المستدامة تضمن عملية تعزيز ثقافة المواطنين بقيم المشاركة والمواطنة

تتضح من خلال مشكلة البحث وخطواته في تحقيق أبعاد المسئولية المدنية للجامعنين( الإسكندرية وفاروس) ويتضح من خلال تفعيل رؤية ورسالة الجامعة، ومدى تمكنيهج من المشاركة في تحقيق وتفعيل أبعاد المسئولية المدنيـة للجامعتين. الأمر الذي دعا الجامعات إلى ربط المسئولية المدنية ور ابطها بالجانب التطبيقي و النظري بمقررات الجامعة وتفعيل دور قطاع خدمة المجتمع وتتميـة البيئة بالجامعة بالعهل على غرس ثقافـة العمل التطـوعي، وتفعيـل المسئولية المدنيـة للجامعـة بتهيئة الطـلاب و الأسـاتذة لتحمل مسئوليات المشـــركة و المو اطنة لخدمة المجتمع، للمشاركة المجتمعية في الأعمال التطوعية. 


\section{ب ـ التنمية المستدامة تركز على عملية التعليم وتتمية المجتمع}

يتضح أن هنالك معايير للعلاقة التبادلية بين الجامعة و المجتمع، وللتبادل المنصف بين الأفراد ( طلاب الجامعتين) فالتنمية المستدامة حديثا ركزت التنمية على التأكيد على القيم والأهداف، مثل زيادة توقع الحياة والتعليم، والانصـاف، و الفرص و التركيز أيضـا على الطلب على تنميـة المجتمع التـي تؤكد على النمـاء للدولـة وللمؤسسـات، وكذللك رأس المـال الاجتمـاعي الذي يتكون من العلاقات وروابط المجتمع المحلي، فالتتمية تثتمل على الربط بين ما يجب تنميته [11].

\section{خامسًا: التصور المنهجي للبحث}

\section{يتضمن تحليد نوع البحث وخطواته، ومجتمع البحث وخصائص عينة البحث فيما يلي}

\section{1 - نوع البحث ومنهجه وأسلوبه}

يعد هذا البحث در اسـة تحليلية مقارنـة بالاعتمـاد على منهجين، التحليلي و المقارن وبتحديد الظروف و العلاقات التي توجد بين المتغير ات وبتفسير البيانات. مستخدمة في ذلك أساليب القياس والتصنيف والتفسير[12] ويركز المنهج المقارن على الدر اسـات التشابهات و الاختلافات بين الوحدات الاجتماعية، كما يساعد هذا المنهج الباحثين على تجديد الأجز اء الرئيسية للحياة الاجتماعية والتي ير اهـا المنهج المقارن[13] من خلال عقد المقارنات بين الجامعتين. 2- طرق وأدوات جمع البيانات

من خلال تصميم دليل المقابلة من النواب ووكلاء الجامعتين، وقامت الباحثة بتطبيقه. واحتوى على البنود التالية :

المحور الأول: تضمن البيانات الأساسية للحالات البحث. (الاسم، النوع، الجامعة/ الكلية، المهنة) بينمـا تضمن المحور الثاني: أبعاد المسئولية المدنية للجامعات. وتضمن سبع أبعاد أساسية كالتالي ( المواطنة، خدمة المجتمع، الديمقر اطية، بيداغوجيا التقصي و المداولة، الحريـة الاكاديميـة، تعليم الإنسـانيات). و احتوى المحور الثالث على دور الجامعة في خدمـة المجتمع وتتميـه، ولتطبيق الأبعاد والدور المدني للجامعات، بالإضـافة إلى روية ورسالة الجامعتين و الكليات، وناقش المحور الر ابع: أهم التحديات و المعوقات التي تو اجـه تطبيق الدور المدني للجامعات ( المتمثلة في تطبيق أبعاد المسئولية المدنية للجامعات المصرية). وتم التحقق من ثبات وصدق دليل المقابلة عن طريق عرضها على بعض السادة المحكمين من أساتذة علم الاجتماع[14] للتعرف على مدى ملائمسة الاسئلة مع عنوان البحث وصدق بنوده، وتم إضـافة بنود أخرى لدليل المقابلة مـن السـادة المحكمين كالتنالي التحديات التي تو اجها دور الجامعتين و التي تعوق تفعيل أبعاد المسئولية المدنية للجامعتين، والتحديات التي تعوق الجامعة من تحقيق دور هـا التنموي ورسالتها وأهدافها. بينمـا الطريقة الثانية: فقد 
اعتمدت الباحثة على تحليل البيانات الجاهزة والتقارير الصادرة عن مر اكز خدمة المجتمع وتتمية البيئة للجامعتين الإحصـاءات الرسمية، و المو اقع الإلكترونية، و أدبيات التراث: مجتمع البحث وخصائصه.

\section{مجتمع البحث: ينقسم إلى قسمين:}

أـ التظظيم و التكوين الجامعي للجامعتين ( الإسكندرية وفاروس). ب- كليات العلمية والنظرية بالجامعتين. وبلغ حجم مجتمع العينة

من كليات الجامعين على مستوى كليات القطاع العلمي و النظري بالجامعتين الأسكندرية فاروس، وكانت (أربع كليات ) مفردة لوكلاء الكليات ونو اب الجامعتين لقطاع خدمة المجتمع وتتمية البيئة، وتم مقابلة وكيل خدمـة المجتمع وتتمية البيئة بالجامعتين وبينما تم مقابلة ثلاثة وكلاء لخدمة المجتمع وتتمية البيئة في جامعة الاسكندرية و هما (وكيل كلية الآداب، والتجارة) لقطاع خدمـة المجتمع وتتميـة البيئة، بالإضافة إلى وكيل الجامعة لقطاع خدمـة المجتمع وتتميـة البيئة من أفر اد عينـة البحث، وبلغت نسبة العينـة التي تم مقابلتهم في جامعـة الإسكندرية ( ثناثة)، حيث تم اختيار كليتي (التجارة والصيدلة) بجامعة الإسكندرية، وبالمثل تم اختيار كليتي( العلوم الإداريـة والمالية، و الصيدلة والتصنيع الدوائي) بجامعة فاروس، عينة إلى تفضيل الباحثة بإجر اء مقابلات فرديـة متعدقة مـع وكلاء ونواب الجامعتين، وتم التطبيق الميداني للبحث الحسالي على قطـاع خدمـة المجتمع وتنميـة البيئة، و عليـه فإن نطـاق البحث بركز على كليـات قطـاع النظـري و النطبيقي للكليات المختارة بالبحث كليتي ( التجارة و الصيدلة) هما نفس الكليتين بجامعة فاروس مع اختلاف المسمى وفقا للهدف الثاني

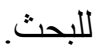

\section{2 - عينة البحث، ومبررات اختيارها.}

أـ أسلوب اختيار العينة. تم اختيار العينة عمدية بأسلوب الإتاحة للباحثة وتكونت من (7) مفردة من أفر اد العينة. بـ مبررات

نظرًا لتعاون وكلاء الجامعتين مع الباحثة أثناء إجر اء رسالته الماجستير الخاصة بها حيث أثنار موضوع الرسالة قضية مهــة وتم البحث فيها بـالتز امن مـع در اسـة موضـوع الرسـالة. ومن ثم فقد رغبت الباحثة بتنـاول القضية البحثيـة المهمـة وهي "أبعـاد المستولية المدنيـة للجامعات المصرية" لجامعتي الإسكندرية وفاروس.

تضم الجامعة مختلف الكليات ذات التخصصـات المتعددة، بالإضافة إلى بعض التخصصات الفريدة التي تنفرد بها جامعة فاروس الخاصـة عن سائر الجامعات المصرية، وذلك فهي تتضمن طلابا من مختلف المجتمعات الحضرية والريفية المستحدثة والطلاب الدوليين، الأمر الذي يتيح للباحثة إجر اء در اسة مقارنة وفقا للبحث الامبريقي عن أبعاد المسئولية المدنية والدور المدني للجامعات المصرية الحكومية و الخاصـة في جمهوريـة مصـر العربيـة. لذللك فالجـامعتين يضفيان على البحث قدرًا مـن الموضـوعية ويضـفي على البحث قدر ا مـن 
تقارب الجامعتين حيث أنهما يقعان في محافظة واحدة الإسكندرية مما دعي الباحثة لإجر اء هذا البحث، وللإجابة على التسـاؤل الرئيسي للبحث، ومعرفة مدي تحقيق البحث للأهداف المقترحة من و اقع تحليل البيانات و المقابلات الحرة التي أرتها الباحثة مع أفر اد عينة البحث. و همـا وكـلاء الجـامعتين لخدمـة المجتمـع وتتميـة البيئة وكـلاء كليتـي (التجـارة و الصـيدلة) لقطـاع خدمـة المجتمع وتتميـة البيئة لجامعـة الإسكندرية، و عمداء كليتي ( العلوم الإدارية و المالية، و الصيدلة و التصنيع الدوائي ) للجامعة فاروس. [15]

2 - مجالات ابحث

المجال المكاني للبحث: تم اختيار جامعتين (جامعة الإسكندرية وهي جامعة حكومية، وجامعة فاروس الخاصة) ويقعان في نطاق محافظة الإسكندرية، مجالا مكانيا للبحث الراهن.

لمحة جغرافية عن جامعة الاسكندرية في محافظة الاسكندرية إحدى أكبر الجامعات في مصر ، وثالث جامعة أنشأت بعد جامعة القاهرة و الجامعة الأمريكية بالقاهرة. وتضم أكثر من 20 كلية في مصر خارجها مطروح، ومن المقرر إنشاء فروع أخرى خارج مصر في جوبا في جنوب السودان. [16]. بينما تحتوي جامعة فاروس على 11 كلية متخصصة، فهي صر ح تعليمي سكندري بمدينة الاسكندرية تلك المدينة المصرية المتميزة، وتلتزم الجامعة بتقديم خدمة لأهل الاسكندرية وتم التطبيق على الكليات الاتية ( الصبدلة والتصنيع الدوائي، العلوم المالية والإدارية).

المجال البشري: عنة عمدية عن طريق الإتاحة للباحثة وتكونت (7) مفردة من أفراد عينـة البحث، وكيل كل من كلية التجارة و الصيدلة) بجامعة الإسكندرية، بالإضافة إلى وكيل خدمة المجتمع وتنمية البيئة لجامعة الإسكندرية وفاروس، ونائب جامعة الإسكندرية، و عمداء كليات ( العلوم الإدارية و المالية، والصيدلة و التصنيع الدوائي) لجامعة فاروس، نظرا لأهميـة منصب السلطة التنفيذيـة والاداريـة العليا بالجامعتين، لتوضيح أهمية تطبيق أبعاد المسئولية الاجتماعية والمدنية. المجال الزمني: تم إجر اء هذا البحث في الفترة الزمنية عام (2015- 2016 ) [17] المحور الثاني: الدراسات السـابقة الخاصة بالمسئولية المدنية والدور المدني للجامعات (الإسكندرية وفـاروس) ومناقثتها. تتناول الباحثة فيما يلي بعض الدر اسات السابقة ذات الصلة بموضوع البحث الحالي، وقد تم تصنيفها إلى محورين، وهما: دراسـات تتاولت أبعاد المسئولية المدنية للجامعات، ودراسات تناولت دور الجامعات و التحديات التي تواجها. وقد تم ترتيب الدر اسـات ترتبئًا زمنيًا من الإقدام إلى الأحداث. 
أولًا: دراسات تناولت أبعاد المسئولية المدنية للجامعات 1 - هدفت دراسة: (Thornton, Courtney H,2006) [186 للتعرف على المعتقدات المؤسسية السـائدة حول المسئولية المدنية ولفهم الكيفيـة التي تسـه في ثقافـات المؤسسية على النهج فريد للمسؤولية المدنيـة، وتحديدًا لمجـالات التنميـة. در اسـة اثثوجر افيـة، تضـنت المقابلات، و الملاحظات الميدانية وتحليل الوثائق. واستخدمت استبيانات. ثانيًا: يهتم بالدراسات التي تناولت دور الجامعات والتحديات التي تواجهها 1 - كما هدفت دراسة: ( زياد بركات أحمد عوض,2011) [19] إلى استطلاع رأى عينة من أعضـاء هيئة التدريس في بعض الجامعات الغربية حول واقع الدور التنموي الذي تمارسه عن طريق تطبيق الاسنبيان لتقيم دور الجامعة في تنمية مجتمع المعرفة. وتوصلت لدور الجامعـات العربيـة، وفقًا لتقدير ات أعضـاء هيئسة التدريس وأثبتت النتـائج وجود فروق دالـة إحصـائية بين الجنسين في تقديرات دور الجامعات العربية في مجال إعداد القرار. ودور الجامعات.

2 - دراسـة:( محمود ذكي جـابر، ناصـر على المهدي، بعنوان: دور الجامعـات في تعزيز مفـاهيم المسئولية الاجتماعيـة لدي طلبتها، 2011):[20] تهدف الدراسة إلى بيـان كيفية تعزيز مفاهيم المسئولية الاجتماعية عبر الجهات الفلسطينية والمصرية، وتحديد مفاهيم المسئولية الاجتماعية. واستخدمت المنهج الوصف. وتوصلت الدراسة النتائج إلى أن هناك ارتفاعاً كبيراً ملحوظا في استجابات العينة من الثـباب الفلسطيني و المصري (عينـة الدراسـة ) على فقر ات وبعد المسئولية المجتمعيـة، إذ بلـغ المتوسط العـام ( 3، 28) بـانحر اف معياري بلغ (5، 91). و أن هناك ميلاً و اضحاً للوعي بالقضايا المجتمعية لدي الثباب الجامعة الفلسطينيين (عينة الدراسـة ) بشكل أكثر من الشباب الجامعي المصري، وتؤكد الاستجابات على بعض الفقرات. 3 - 21] (2015, Alaa Tag Eldin Mohamed ) دراسةة

هدفت وضع إطار للمسؤولية الجامعة والاستدامة مع التركيز على جامعة جنوب الوادي كدر اسة حالة للجامعات المصرية. و التعرف على أهم المعوقات التي تواجـه الجامعة، و استخدمت دليل مقابلة مع 12 نائبا والوكلاء. وأظهرت النتائج أن الجامعة تعمل على دمـج المسؤولية الاجتماعية والاستدامة في الخطط الاستر اتيجية ولكن مجزأة

4 - دراسة: ( مرفت مسعود جاب الله على قطوش، 2016)[22] هدفت للتعرف على المسئولية الاجتماعية للجامعات المصرية ودور ها في تنمية المجتمع المحلى. واعتمدت على نظريتي التنمية المستدامة ور أس المال البشري لتحقيق أهداف الدراسـة وتسـاؤلاتها. تنتمي إلى البحوث الوصفية التحليلية المقارنة، ويتحدد المجال المكاني للار اسة في جامعتي الاسكندرية وجامعة دمنهور، اعتمدت الباحثة على سحب عينة عنقوديه منمثلة في وكلاء الكليات ونو اب الجامعتين، وبينت نتائج الدر اسة الميدانية قلة المو ارد المادية والمالية. 


\section{ثالثًا: التعليق على الدراسات السابقة فيما يلي عرض لأهم استنتاجات}

أو اجـه اسـتفادة الباحثـة مـن الدر اسـات السـابقة مكنـت الباحثـة مـن صـياغة مششCourtney. و الاسـفادة مـن التوجـه النظـري

و الميداني، حيث انفردت در اسة بحث الباحثة الر اهن على سبعة أبعاد للمسئولية المدنية والتي تم تتاولها بالبحث، و اقتصرت على معرفة البعد المدني أي المسئولية المدنية لجامعتي( الإسكندرية وفاروس) ومكنت الباحثة من وضع تصور نظري لتفعيل تحديات تطبيق البعد المدني بالجامعتين، ويمكن مناقثة أهم الملاحظات التي استنجتها الباحثة من تناولها للار اسات السابقة على النحو التالي:

أ - من حيث الموضوع: ومن خلال العرض السابق أوضحت الدر اسات الأجنبية مثل در اسة (Thornton Courtney .H, 2006) دراسة اثثوجر افيـة التي اهتمـت بموضـوع المعتقدات الثقافية لبعد المسئولية المدنية للجامعات، بينمـا اهتم بحث الباحثة الر اهن در اسـة للأبعـاد المسئولية المدنية للجامعات المصرية (الإسكندرية وفاروس) بينما اهتمت دراسـة:( Alaa Tag Eldin,2016) بموضوع المسئولية الاجتماعية للجامعة، وتم تطبيق الاستبيان للنو اب ووكلاء الجامعة، بينما ركز بحث الباحثة على أبعاد المسئولية المدنية للجامعات، وترى الباحثة المسئولية المدنية أشمل و أعم من المسئولية المدنية. وبينما ركز إعلان تايلوا (Tolloires, Declaration,2005) على الدور المدني و المسئولية الاجتماعية للتعليم العالي، واتفق مع بحث الباحثة الر اهن وهو التركيز على الدور المدني للجامعات.

أما الدراسات العربية اتفقت معظم الدراسات العربية مع بحث الباحثة في الاهتمام بالبعد المدني وهو بعد المسئولية المدنية للجامعات التي اهتمت بالبعد المدني للجامعة اليسو عية، واهتمت در اسـة (زياد بركات أحمد عوض، 2011) بالدور التتموي الذي تمارسـه الجامعة في تنميـة المجتمع و اتفقت مـع كل مـن دراسـة محمود ذكي جـابر، ناصـر على المهدي) على دور الجامعـات في تعزيز مفاهيم المسئولية الاجتماعية لطلابها، وركزت على الجامعات الفلسطينية و المصرية. ب ـ مـن حيث النظريـة ظهرت بوضوح في الدراسـات العربيـة، 2015 وتتفق الدر اسـة الحاليـة مـع معظم الدر اسـات السـابقة التي تناولت المسئولية الاجتماعية، وركزت عند تناولها للمسئولية الاجتماعية أو المدنية للبعض النظريات التقليدية مثل البنائبة الوظيفية، ونظريـة الدور الاجتماعي، والبعض ركز على النظريات الحديثة مثل التنمية المستدامة ور أس المال البشري.

\section{ج- من حيث الاجراءات الميدانية}

1 - نـوع الدراسـة: تبينت الدر اسـات السـابقة على سبيل المثنال منها دراسـات وصفية، وأخرى وصفية تحليلية، وأخرى مقارنـة، وأخرى اسنطلاع رأي، بالإضافة إلى در اسة اثنوجر افية، واختلفت معظم الدراسات العربية والأجنية مع بحث الباحثة في التطبيق الميداني، حيث اهتم (عدنان الأمين) باستقصاء خطاب المدرسة والمسؤولين و الوحدات غير التعليمية ذات الوظيفة المدنية. واهتمت دراسـة (علاء تـاج 
الدين،2015) بإجر اء در اسـة حالـة على جامعة جنوب الوادي للتعرف على المستولية الاجتماعية للجامعة. بينمـا اهتمت در اسـة (زياد بركات أحمد عوض، 2011) باستطلاع ر أي عينـة من أعضـاء هيئة التدريس في بعض الجامعات الغربيـة، وبعض الدراسـات السـابقة اهتمت باستقصاء خطاب المؤسسة و المسؤولين بالجامعات.

2 - من حيث المنهج المستخلم: اعتمدت معظمها في تحليل البيانات (الجاهزة و على المنهج المقارن، و الاستقصاء و المقابلات، والمسح الاجتماعي، و المنهج الوصفي و التحليلي وفقا لمبدأ المرونة المنهجية)

3 - الأدوات جمع البيانات تعددت أدوات جمع البيانات و التي منها( استمارة الاستبيان، وبعضها على دليل المقابلات الفردية، والأخرى تحليل المضمون، وتحليل المحتوى، استطلاع رأي للمسؤولين، التحليل الكيفي واستخدام دليل المقابلة ) 4 - أما فيما يتعلق بالنتائج فتوصلت تلك الدراسات ولم تحدد نو عية قنوات الاتصال محل الاهتمام، وفي أغلب الأحوال لم تركز على دور وكلاء خدمة المجتمع وتنمية البيئة بل كان التركيز أكتر على أعضاء هيئة التدريس في تقديم الخدمات الاستشارية. والذي يشكل أحد أهم قنوات نقل المعرفة بين الجامعة والمجتمع المحلي. ومن ثم البحث الحالي بركز على تحليل البيانات الجـاهزة للأبعاد المسئولية المدنية للجامعتين. وبينت الدر اسات السابقة ضعف المو اطنة و الديمقر اطية. المحور الثالث: التحديات والمعوقات التي تواجه تطبيق أبعاد الدور المدني في الجامعات المصرية يمكن توضيح الباحثة التحديات التي تترتب على وجود تحديات تعوق الجامعتين من أداء بالكليات المنوط القيام بها، وينظر إليها باعتبار ها تحديات مهددة معرقلـة للأهداف ورؤيـة الجامعـة، ويمكن توضيح الباحثة للتحديات و المعوقات التي تواجهـ الجـامعتين ( الإسكندرية وفاروس )

\section{أولًا: المعوقات التي تواجه الجامعة}

$$
1 \text { - يوجد معوقات إدارية و هي نقص في الموظفين الإداريين بالجامعة. }
$$

2- كثرة أعباء هيئة التدريس بالجامعة حيث لا يوجد قطاع خدمة المجتمع وتتمية البيئة بالكليات.

$$
\text { 3- قلة أعداد لجان متخصصة الكليات النظرية مقارنة بالكليات العلمية. }
$$

4- عدم تحديد بدقة عالية لإدوار القائم بعمل وكلاء الكليات لنشئون خدمة المجتمع بالجامعتين. 5 - عدم وجود لجـان متخصصـة للكليـات وخاصـة لجنـة خدمـة المجتمـع وتتميـة البيئة ونتج عن ذلك قيـام أعضـاء هيئة التـدريس

$$
\text { بالإشر اف على الأنشطة الطالبية. }
$$




\section{ثانيًا: المعوقات التي تواجه المجتمع المحيط}

اتضحت من خلال بعد الجامعة فاروس عن المناطق العشو ائية. مما يتطلب وقت كبير على الطلبة أثناء عمل حملات التوعية والتبرع بالدم أو اجر اء الأبحاث العلمية على هذه المناطق أو تنفيذ الأنشطة الطلابية والأبحاث المجتمية للتنمية المجتمع.[23]. المحور الرابع: التصور المقترح للمسئولية المدنية للجامعات المصرية ودورها في تنمية المجتمع وخدمته

ويهدف التصور المفترح لتفعيل الدور المدني للجامعات، و التعرف على الاحتياجات، والمشكلات التي تواجها المجتمع محاولة التغلب عليها، كما تسعى الباحثة إلى تقديم المفاهيم الإجر ائية للبحث والتوصيات و المقترحات التفعيل ومن خلال العرض السـابق يمكن للباحثة توضيح التصور المقترح للمسئولية المدنية للجامعات المصرية ودور ها في تتمية المجتمع وخدمته، بالتركيز على العلاقات بين الطلاب و الهيئة التعليمية والأساتذة بصورة فردية أو جماعية لتجسيد الاهتمام بنشر أنشطة خدمـة المجتمع، والخدمـة من أجل التعليم و المبني على تنمية وعي الثباب بالقضايا المحيطة للمجتمع. [24]

لذلك ينم تناول المسئولية المدنية للجامعات المصرية من خـلال الرؤيـة والرسـالة فالروئية ": التصور الذي تتوخي أن تبو أه في العملية سواء في المجتمع المحلي أو العالمي أو بالنسبة لغير ها من مؤسسات مناظرة، وكذلك خططها المستقبلية، أما الرسالة؛ فتعني تحديد مهام المؤسسـة وخصائصـها المميزة بدقة مبينـة، ودور هـا في إثباع حاجـات المجتمع الذي يخدمه وخصـائص الطالب الذي تقبله مو اصفات الخريج الذي تعده والإطار الثقافي، والأخلاقي الذي تحرك فيه والأوليات التي تحظي باهتمامها ويمكن نوضيح المسئولية المدنية والدور المدني من تفعيل بعد خدمة المجتمع و هو التعليم القائم على تقديم خدمات وأنشطة للمجتمعات، وتظهر من خلال المساهمة في حمـات الرعايـة الاجتماعيـة أو محو الأميـة أو الاهتمـام بالبيئـة أو مشـاركة الهيئـات التعليميـة في مجـالس عامـة وبـر امج اجتماعيـة أو منظمـات تطو عية.[25] ويمكن توضيح الباحثة المسئولية المدنية للجامعات المصرية مما سبق ذكره أن المسئولية المدنية والتنمية المستدامة قربين، فالأول يعني دمج نشاطات الأفراد في المجتمع ومواطنة الأفر اد داخل الجـامعتين من خـلال المشـاركة الاجتماعية و التطوع، بينمـا يتطلب الثاني المو افقة بين جميع الجو انب للتحقيق التنمية البشرية المستدامة[26]، فالمسئولية المدنيـة تحل محل المواطنـة المدنية لمرحلـة التعليم المدني الذي يحس المو اطنين على المشـاركة في الحياة العامـة للايمقر اطية، لاستخدام حقوقهم والوفاء بمسئولياتهم بالمعرفـة والمهارات اللازمة لتقدم أي مؤسسة فتهتم المدارس الأمريكية بمهمة و إبعاد المسئولية المدنية اهتمامـا متميزًا منذ الأيسام الأولى لهذه الجمهوريـة من خلال التعليم. وكخطوة واحدة من هذه العملية التعليمية، وقد خلق التعليم العالي افتر اض مهمة لتعزيز روح القيادة للمواطنين، والمشـاركة 


\section{يتضمن التوجه المدني للجامعة سته مؤشرات تظهر على النحو التالي}

\section{Citizenship 1}

يعرفها ( غيث، 1995) على أنها علاقة محكومـة بالقانون بين الفرد والدولة يقدم فيها الفرد الولاء، وتقدم الدولـة الحمايـة[28]. بينمـا عرفتها دائرة المعارف البريطانية بأنهاعلاقة بين الفرد و الدولة كمـا يحددها قانون تلك الدولنة، وبمـا تتضمنه تلك العلاقة من واجبات وحقوق في تلك الدولة، وتؤكد على المسئوليات وتولي المناصب العامة.

تتضح من خلال تفعيل أبعاد المسئولية المدنية وتدعيم قيم المواطنة لدي الطلبة وضمان استقرار ها وأمنها وتفهمها، حيث يثعر جميع أفر اد المجتمع بأنهم متساوون في المكانة والتفاعل والفرص فالمواطنة مهمة في مسيرة التنمية [29]، ولا تقوم المواطنة على أساس تمتع الفرد بحقوقه في المجتمع، ولكنها تعني الثر اكة المجتمعية وتحمل الفرد لمسئوليته مع مجموعة المجتمع تجاه معدلات التنمية.[30] وتعرف "michalis kakos " المو اطنة قائمسة على خدمة التعلم ومنهجيـة التدريس المبتكرة التـي تدمج خدمـة المجتمع مـع الدراسـة الأكاديمية لتعليم إثشر الك المجتمع المحلي، و إثراء والتعلم. تعزيز المجتمعات المحلية يجب أن تكون خدمة التعلم جهد تعاوني بين المجتمع و الطلاب لتحقيق أهداف التعليم الأصيلة.[31]

\section{2 - خدمة المجتمع: Community service}

خدمـة المجتمـع بالعمليـة التي يتم من خلالهـا تمكين أفر اد المجتمع وجماعاتـه ومؤسسـاته و هيئاتهـه من تحقيق أقصـي استفادة ممكنة من الخدمات المختلفة التي تقدمها الجامعة بوسائل و أساليب متنو عة تتناسب مع ظروف المستفيد وحاجاته الفعلية[32] ويمكن للباحثة توضيح أربع نماذج متبعة في الجامعات الغربية على سبيل المثال

\section{النموذج الأول: يتضمن المشاركة في الأعمال التظوعية التي تخدم المجتمع}

يستفيد منه الطلاب في المشاركة في الأبحاث في نواح كثيرة، ويكون لديهم القدرة على المنافسـة عند التطبيق و لا تحسب ضمن أرصدة هذا النماذج فلوريدا في الو لايات المتحدة[33] بينما النموذج الثاني: يتضمن نقاط خدمة المجتمع التي حصل علهها الطالب أثناء دراسته حيث تحتسب ضمن مجموع النقاط المطلوبـة للالتحاق النظام المتبع في الجامعة الأمريكية الكاثوليكية [34]، ويشمل النموذج الثالث: النظام المتبع في الجامعتين (الإسكندرية وفاروس) و الذي يتضح هذا النظام من خلال الاشتر الك في الأنشطة التي يقوم بها الطلبة بصورة تطوعية سواء فرديـة أو جماعية من خلال مكتب أنشطة الطلاب و الوحدات الجامعية، وهي لا تحتسب كأرصدة أو كنقاط إلا أنها في جامعة فاروس تخضع للنماذج الثاني. بينما يتضمن النموذج الرابع فكرة الخير المشترك ويعتبر نمـاذج حديثًا لخدمة المجتمع، والذي 
ويتطلب ذللك دعم النزوع المجتمي وتشجيع خدمة المجتمع الفردية والجماعية.[35] ويمكن ملاحظة مدى اختلاف الجامعات الحكومية و الخاصة و غير ها من مؤسسات التعليم للمرحلة الثانويـة والتي تخضـع لاختصـاص وزارة التعليم العالي، فإن كل قطاع يعمل بموجب سلطة قانونية مختلفة فجميع الجامعات الحكومية تنظم أعمالها وفقًا للقانون رقم 9 ؛ الصـادر في عام 972 (، وتخضـع لو لايـة المجلس الأعلى للجامعات. وجميع الجامعات الخاصة تعمل في إطار القانون رقم. [36]

فالجامعات عادة تقوم بمهمتين أولهما" التعليم والبحث "، فتسمى بالجامعات البحثية المتخصصة، وتركز فيها بشكل رئيس على البحوث و الدر اسات العليا، ومن جهة أخرى؛ تقويم بر امج بحثية متميزة في مجالات استراتيجية، مـع تقسيم بر امج المر احل الجامعيـة. ثانيهما "جامعات التعليم " فتسمى بالجامعات التدريسية، وتهنم بشكل رئيس ببر امج بحثية منميزة في مجالات استر اتيجية مـع تقسيم بر امج المر احل الجامعيـة، ولكنهمـا عمليا تلعب دورًا ثالثًا هي الجامعـات الثـاملة القائمـة على البحث و التدريس لخدمة المجتمع وتنميـة البيئة. [37]

Democracy - الايمقراطية:

ظهرت بشكل شبه قوي في الجامعتين من خلال اشتر اك الطلبة في تنفيذ الانشطة المجتمية في كليثي التجارة والصيدلة بالجامعتين. أ - المشاركة في أتخاذ القرارات: Participation in decision -making

تعرف بأنها تلك الأنشطة المتنو عة التي يمارسـها شخص مـا بالاشتر اك مـع أشخاص أخرين، ومعناهـا القدرة على الانخر اط الكامل في الحياة المجتمعية للجامعة [38]، وتقوم الجامعات بتنظيم عديد من الأنشطة والبر امج، والدورات التدرييية لأعضاء هيئة التدريس، ولتنمية قدر اتهم، وتطوير إمكانياتهم للوصول إلى مستوي الجودة في التعليم، وتمكنيهم من أداء دور هم بفاعلية وتحقيق الهدف من التدريس الجامعي، كما تعتبر الجامعات المؤسسات الأكثر أهمية في تحقيق احتباجات المجتمعات ومتطلباتها من حيث الر أسمال البشري، إذن لا تقتصر الجامعات كمؤسسـات اجتماعبـة على تأمين الخدمات التربويـة فحسب، بـل يتعداه لتشمل خدمة المجتمعات غير تحمل مسئولية المشاركة الفاعلة ويتحقق ذلك؛ من خلال نوسيع نطاق بر امج المشـاركة المدنيـة والمسئولية المدنية بطريقة أخلاقية في عملية التدريس و البحث العلمي و الخدمة العامة، لخلق أطر مؤسسية لتشجيع ومكافأة وتقدير الممارسـات الجيدة في مجال الخدمة الاجتماعية من جانب الطلاب، و هيئة التدريس، و العاملين وشـركائهم في المجتمع هذا من جانب أخر [39] لذلك؛ فهناك اعتر اف من المجتمع بـأن مؤسسـات التعليم العالي " الجامعات " تختلف بنسبة كبيرة سواء في الهياكل المعماريـة، أو المناخ التنظيمي والجامعي السـائد فيها. ووفقًا لإعلان تايلوا، قد ترجع مشكلة الجامعات المصرية في ضخامة أعداد طالبها قباسًا لتعدد الجامعات، و عدد أعضـاء هيئة التدريس. ويعتبر هذا التز ايد مشكلة من المشاكل التي يعاني منها الطلبة والاساتذة بالمقارنة مع أقارنهم تجعلهم لا يو اصلون تعلمهم وعملهم بصورة جيدة. وهذه 
المشكلات قد تعود إلى عوامل أكاديمية ومهنية أخرى (Talloires, Declaration, 2005)] يجب أن يشمل الدعم المالي و التعليمي الملائم لتلك المجتمعات من الفقراء و المهمشين. و التعليم العالي توسيع نطاق تدريب المعلمين، سواء قبل الخدمة و أثناء الخدمة، مع المناهج التي تجهز المعلمين لتزويد الأفراد بالمعرفة و المهارات التي يحتاجونها في القرن الحادي و العشرين. وهذا يتطلب مقاربات جديدة، بما في ذللك التعليم المفتوح.[41]

4 - بيداغوجيا التقصي والمداولة: Pedagogy of inquiry and deliberation

ظهرت بصورة واضحة في الجامعتين من حيث اثتر الك الطلبة في حل المشاكل التي تواجه المجتمع المحيط وبتنفيذ بعض الأبحاث العلمية بمشاكل الطلبة. وتتضح من خلال التدريب على تنفيذ الأبحاث العلمية للمساهمة في حل المشاكل التي تواجه المجتمع، بينما ظهرت بصورة أقوى في جامعة فاروس لاتباع الجامعة نظام الأنثطة الثشهرية في تنفيذ الأبحاث العلمية وبتنفيذ و إثراف أعضاء هيئة التدريس و المساهمة في مجال التطبيق.

5 - كُقة القانون: Law culture

يختلف مفهوم ثقافة القانون بين الجـامعتين وفقًا للنظام القو اعد المتبعـة حيث ظهرت بصسورة ضـعيفة في الدقرارات الدراسية في الجامعتين، وتجدر الإشارة إلى أن ثقافة القانون المؤسسي محدودة وذلك؛ لعدم توافر القو انين المتاحة على الموقع الإلكتروني للجامعتين، و التي انعدمت في كليتي جامعة الاسكندرية والتي اتضحت من خلال الإطلاع على البيانات الجاهزة، وظهر في تقارير مجلة صوت جامعة فاروس لكلية الصيدلة ومتاحة إلكترونية.

6

أكد الإعلان " ليما" الصادر عام 1988 أن الحرية الأكاديمية تعني حرية الاعضـاء الأكاديميين، فرديًا أو جماعيًا، في متابعة المعرفة وتطوير هـا وتحويلها، من خلال البحث و الدر اسـة، والمناقتشة، و التوثيق، والانتاج، و الخلق، و التدريس، و إلقاء المحاضر ات، و الكتابة. و "المجتمع الاكاديمي" يغطي جميع أولئك الاثخاص الذين يقومون بالتنديس، والدراسة و البحث، والعمل في مؤسسة للتعليم العالي. "الاستقلال" يعني استقلال مؤسسات التعليم العالي عن الدولة وغير ها من قوى المجتمع، وصنع القرارات المتعلقة بسير العمل الداخلي فيها وبماليتها و إدارتها، وإقرار سياساتها للتعليم والبحث والإرشاد و غير ها من الأنشطة ذات الصلة. أما "مؤسسات التعليم العالي" تتكون من الجامعات وغير ها من مر اكز التعليم ما بعد الثانوي وما يرتبط بها من مر اكز البحث والثقافة.[42] ومن العرض السـابق يمكن للباحثة توضيح أن الحريـة الأكاديمي تغني حرية التفكير لأساتذة الكليات والجامعات و آخرون من المجتمع التعليمي، وحريتهم في متابعة المعرفة لتوصيل الخدمة لأهالي المجتمع عن طريق البحث العلمي بالدر اسة، و إلقاء المحاضرات، 
و الكتابة، والتدريس، و التوثيق الانتاج والابداع. والحرية الأكاديمية هي شكل متميز من الحريات وهي بذلك ليست بالضـرورة امتـداداً لحرية العقيدة والرأي والتعبير و التجمع كما أكدت عليه المواد (18، 19 ، 20) مـن الإعلان العالمي لحقوق الإنسان و المؤتمرات.

أوضحت البيانات الجاهزة قلة الاهتمام بالحرية الاكاديمية في الاسكندرية نظرًا للبعض المعوقات التي تواجهها، بينما ظهرت بصورة منخفضة في جامعة فاروس من حيث القيام بالأبحاث العلمية.

أكدت النتائج أن هناك ارتباط بين الحرية الأكاديمية وأهداف الجامعتين. كما أكدت النتائج على حرية أعضاء هيئة التدريس في الإسهام

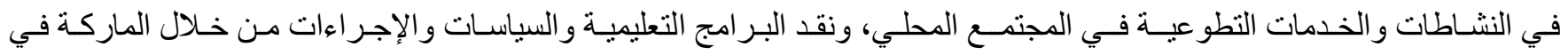
المؤتمرات الدولية و المحلية بالأبحاث التعليمية، وكما لهم الحق في إبداء الرأي في التععيينات الإداريـة والجامعية، وبالإضـافة إلي إيصـال اقتراحاته من خـلال القنوات المناسبة للـإدارة الجامعيـة".

\section{7 - تعليم الإنسانيات: Humanities Education}

يتضح الاهتمـام بالقضـايا البيئة ومثـاكلها من خـلال عقد بعض المؤتمر ات مثل المؤتمر السنوي للكلية، وهدف لمعالجة القضـايا المجتمعية والبيئية، بالتنسيق من قطاع خدمة المجتمع وتتمية البيئة وتتميز الكلية عن غير ها من كليات محل البحث في عمل تصميم استيانات دورية لقياس رضاء المستفيدين من أعضاء هيئة التدريس، والهيئة المعاونة والعاملين، كما ظهرت من خلال اكتساب الطلبة مهار ات تساعدهم على تنفيذ حملات التفاعل مع مؤسسات المجتمع المدني ومن خلال تدريب الطلاب في المؤسسات الخارجية مثل:" البنوك والصندوق الاجتماعي، و الصحف و المصانع ومر اكز الأبحاث ". وتفعيل وتنظيم دور ات لاكتسابهم المهارات البيئية والخبرات المعرفية المختلفة، وأيضًا دعوة مؤسسات المجتمع المدني من الخارج للمشاركة في فعاليات الملتقي الوظيفي، بالإضـافة إلى دعم التعاون بين الكلية ومؤسسات المجتمع المحيط.[43]

من حيث الجانب التطبيق لأبعاد المسئولية المدنية في الجامعتين( الإسكندرية وفاروس ) أولَا: يمكن توضيح ما المقصود بروية ورسالة وأهداف الكلية في الجامعتين 1 - جامعة الإسكندرية: سوف تتناول الباحثة روية الجامعة والتي تتضح في السعي إلى التميز إقليميًا وعالميًا في مجالات التعليم والبحث العلمي الصيدلي وخدمة المجتمع وتتمية البيئة، و الحصول على الاعتماد. 2 - رؤية جامعة فاروس: تطمح جامعة فاروس في أن تكون واحدة من أبرز الجامعات في المنطقة، وعلى المستوى الدولي لتلبي احتياجات المجتمع، وتو اكب التطور التكنولوجي المستمر، وتتمي قدرات طلابها التعليمية والمهنية والبحثية والقيادية، تهدف رسالة جامعة فاروس إلى توفير فرص تعليمية ذات مستوى متميز تساعد الطلاب على تنميه ونطوير مهار اتهم ومعارفهم وتمكن خرجيها من خدمة مجتمعاتهم 
و تطوير إنتاجية مؤسساتهم من خلال تحقيق التكامل بين القدرات التعليميـة والبحثية و التطبيقيـة. [44] انطلاقًا من الرؤيـة والرسالة فان الجامعة تسعي لتحقيق أبعاد المسئولية المدنية من خلال تحقيق أنشطة الطلابية وتتضح رسـالة الجامعة في السعي لتوفير فرص تعليمية ذات مستوى متميز تساعد طلاب الجامعة على تتميه وتطوير مهار اتهم ومعارفهم، وتمكن خديجيها من خدمة مجتمعاتهم وتطوير إنتاجية [45]. مؤسساتهم بتحقيق التكامل بين القدرات التعليمية والبحثية و التطبيقية ثانيًا: كلية التجارة في الجامعتين ( الإسكندرية وفاروس ) 1 - تتضح رسالة كلية التجارة في جامعة الإسكندرية تتيح الكلية لطلابها تعليم عـالِ متميز في مجـالات الأعمال وفقًا لمعايير الجودة العالميـة، مما يمكنهم من التطوير المستمر لمعـارفهم وخبر اتهم ومهار اتهم، بهدف خدمة المجتمع من خلال التعاون و التكامل بين الجهود التعليمية والبحثية. الرؤية: تتطلع الكلية لتصبح مركزًا بارزًا للتعليم و التعلم في مجالات الأعمال بالمنطقة و العالم، وتعد طلابها للقيادة الاداريـة الحديثة مرتبطة بالنطورات في عالمنـا المتر ابط. [46] انطلاقا من رؤية ورسالة الكلية فإن الكلية تسعي لتحقيق أبعاد المسئولية المدنية 2 - بينما تتضح رسالة كلية الدراسات المالية والادارية بجامعة فاروس: تسعى لتحقيق رؤية الجامعة وأهدافها بفاعلية وتعتبر الكلية واحدة من الكليات القلائل التي تهيئ الخريج لمستقبل وظيفي باهر مما يساعده في الحصول على مركز مرموق ومميز داخل مجتمعنا.

\section{ثالثا: مؤشرات المسئولية المدنية في جامعة الإسكندرية فتظهر على النحو الآتي:}

1 - الايمقراطية: تكوين المعارف و المهار ات المكتسبة لنشر الوعي الصحي بين كافة الأطر اف المعنية داخل وخارج الكلية، و اشتر اك الطلبة في تنظيم الندو ات بشأن التوعيـة الصحية للطلاب و العـاملين بالكلية، وتتظيم ورش عمل التوعيـة الصحية بـالكلي وقو افل الطبية للقري الأكثر احتباجًا بالتنسيق مع قطاع خدمة المجتمع وتنمية البيئة ومؤسسات المجتمع المدني. ويمكن توضيح روئة " ألبرت ويل" الذي يذهب إلى أن الديمقراطية هي نظام للتحكم. ويعتمد في اتخاذ القرارات المهمة حول المسائل القانونية والسياسية في داخل الدولة، على الر أي العام يقوم المواطنون بـالتعبير عنهـهـ رسميًا في المجتمع. وبطرق [47] مباشرة وغير مباشرة. 2 - المشاركة في اتخاذ القرارات: ظهرت من خلال تلبية احتياجات مجتمع الكلية والاشتر اك السنوي للطلبة في تنفيذ الأنشطة المجتمعيـة من حفل الخريجين بصفة دورية، و إتاحة الفرصة للمشاركة الطلاب في الدورات التدريبية للخريجين، والمشـاركة في الاحتفال بيوم اليتيم ( بالتنسيق مع رعاية الثباب)، و المشـاركة في فاعليات الأسبوع البيئي بالتنسيق مع مركز خدمة المجتمع بالجامعة. و عقد الدورات في 
3 - المشاركة: ظهرت من خلال اثتر الك الكلية مع الجامعة في المؤتمرات الدولية والمحلية، في المؤتمر الدولي لتطوير الأعمال والابتكار. كما ظهرت وتتضح عملية " المشـاركة" من خـلال مشـاركة أكثر من مائة باحث على مستوى عشرة دول في المؤتمر الذى احتضنته جامعة فاروس بقاعة المؤتمر ات المجهزة بأحدث الوسائل السمعية والبصرية.

\section{المساهمة في تنمية الموارد المالية بالكلية}

تفعيل دور وحدة البحوث و الدر اسات التجارية في تقديم خدمات المجتمع مثل المحافظة و البنوك والشركات و المصانع في مجالات دراسـة الجدوى وتقديم الاستشـار ات، وعقد دورات تدرييـة متخصصـة لجهات خارجية في مجـال المحاسبة. و العمل على زيـادة برونوكو لات التعاون المشتركة بين الكلية ومؤسسـات المجتمع. وتسويق إمكانيات وقدرات الكلية الاستشـارية و البحثية و التدريبية، وتتظيم معارض خيرية. وتتمتع الكلية برضي المؤسسات التعليمية ومؤسسات المجتمع المدني ذات العلاقة عن أدائها المؤسسي ومستوى الخريج وبمتابعة مقترح التقويم الذاتي للطلاب.[48] اتضح من خلال الاطلاع على البيانـات الجـاهزة تحقيق أبعاد المسئولية المدنية للجامعتين بما يتفق مع رؤيسة ورسـالة الجامعتين، حيث أوضح ذللك من خلال الكتيب الخاص بالكليات و البيانات المتاحة على شبكة الانترنت، ويتو اجد بكل إدارة دليل للكلية يتضمن تحديدًا للمهام الوظيفية القيادية والأكاديمية و الإدارية و الفنية. وتمثل الأساس للعمل بالوظائف المختلفة داخل المؤسسة، وهذا التوصيف مشتق من لوائح الكلية وقانون الجامعات بما يضمن التو افق بين سياسات العمل والقو انين.

\section{4 - ثقافة القانون في جامعة فاروس}

فقد عرفها "أوجبرن" بأنها كل ما يشتمل على الأشياء والنظم الاجتماعية والطريقة الاجتماعيـة الني يسير عليها الناس في حياتهم إذن فالثقافة فكر و علم ومعرفة، ترتبط بقضايا المجتمعات.[49] وتتضح من خلال الثق الميداني للثقافة القانون في هذا البحث على النحو التالي لا يسمح لأي طالب أن يتناول كتب أو مذكرات دراسية تحمل اسم صـاحبها داخل الكلية، دون أن تكون متعلقة بحمايـة رقم إيداع محلي أو دولي، ويسمح بتناول المذاكرات الدراسية التي يقوم بها أو الكلية بتجهيز ها للطلاب للإر اض علمية دون أن يكون منقولة مباشرة على أن يكون معتمدة من مجلس القسم الخاص. تقوم بنشر الوعي بالقو اعد و القو انين المنظمـة للحفاظ على حقوق الملكيـة الفكريـة والنشرين أعضـاء هيئة التـدريس و الهيئة المعاونـة، و الطلاب و الاداريين عن طريق توزيع هذا النموذج. تلنزم الكلية بجميع أقسامها والمكتبات العامة بما يتطبق جميع أحكام القانون رقم 82 لسنة 2002[50] ودعوة لجميع الطلاب بالمشاركة في العرض المسرحي للملتقي الكلية لعام2015 ـ 


\section{الاستتناجات والمناقثنات: تستتج الباحثة من العرض السابق للجامعتين ( الإسكندرية وفاروس )} أن جامعة فاروس في حاجة لتفعيل دور ها لخدمة المجتمع. بالإضافة لتفعيل بعض أبعاد المسئولية الددنية التتسيق و التعاون بين كل الكليات في تتفيذ الأنثطة الطلابية. وضرورة تفعيل هيئة معاونة لوكيل الكلية لثشئون خدمة المجتمع نظر العدم وجود منصب وكيل خدمة المجتمع وخدمة المجتمع لكليات الجامعة. أمـا فيما يتعلق بالمواطنة في الجامعتين ظهر مفهوم المو اطنة بقوة وارتباطه بخدمة المجتمع في جامعة فاروس، بينما تتضح المواطنة في جامعة الاسكندرية وعقد دورية لنشر تثتنل على التو عية البيئية و المجتمعية بالكلية بين أعضاء هيئة التدريس والعاملين و الطلاب. رابعًا: فيمـا يتعلق بأبعاد تطبيق وتفعيل المسئولية المدنية بكلية الصيدلة في الجامعتين(الإسكندرية وفاروس)

أ - رسالة ـ كلية الصيدلة - جامعة الإسكندرية، ورسالة الصيدلة والتصنيع الدوائي بجامعة فاروس سوف توضح الباحثة رسالة الكلية والتي تتضح من خلال تهيئة البيئة التعليمية والبحثية لمو اكبة التطور المتنامي في مجالات التعليم و التعلم و التنريب و البحث العلمي، وذلك لإمداد نظام الرعاية الصحية بعلماء متخصصين وصيادلة قادرين على ممارسة متطورة لمهنة الصيدلة ومواجهة التحديات المطردة لها. كما تسعى الكلية إلى إقامه شر اكة ديناميكية تسهم بفعالية في تطوير الصناعة الدو ائية وخدمة المجتمع وتنمية البيئة. ر رسالة كلية الصيدلة و التصنيع الدوائي ـ لجامعة فاروس - من خلال تهيئة البيئة التعليمية وتهدف إلى توفير فرص تعليمية ذات مستوى متميز تساعد الطلاب على تتمية وتطوير مهار اتهم ومعارفهم وتمكن خرجيها من خدمة مجتمعاتهم وتطوير إنتاجية مؤسساتهم من خلال تحقيق التكامل بين القدرات التعليمية والبحثية والتطبيقية[51] وفيما يتعلق بتطبيق ابعاد المسئولية بالكلية تتضح فيما يلي:

1 ـ الحرية الأكاديمية: تعني بالمفهوم الحديث حرية التفكير لأساتذة الكليات وآخرون من المجتمع التعليمي، أما الحديث عن حرية العقل، فهي فكرة قديمة ذات تاريخ طويل.[52] فالحرية الأكاديمية استقلال الكليات و الجامعات إداريا وحرية الأساتذة فيها بحرية التدريس، والبحث، و إبداء الر أي، تعطي الطالب الحق في حرية الاختيار ، والتعلم و التعليم دون تمييز. وتثثير نتائج الدراسـات السابقة إلى أهمية الحريـة الأكاديمية في تطوير المناهج، بالإضافة إلى أنها حق من الحقوق المشرو عة للباحث و المفكر والمثقف فهي تسهم في زيادة المعارف و التعليم و البحث عن الحقيقة و التعليم من خلال فتح أبو اب الحوار النافع و النقد البناء والتعبير. [53] كمـا تثـير نتائج البحث الراهن من واقع مقابلات أفراد عينة البحث إلى مسئولية الجامعة من الضرورات المهمة لنجاح العملية الأكاديمية سواء داخل الجامعة أو خارجها 
حيث تتضح مسئوليتها في انتقاء و إعداد أفضل الصيادلة المؤهلين بالمعارف المتخصصة والمهار ات المهنية والقيم الأخلاقية المبنية على معايير قياسية. ودعم الدر اسات العليا و البحث العلمي بأقسام الكلية، وذلك بتطوير البر امج الدراسية والخطط البحثية. و احتر ام وتشجيع مشاركة الطلاب في المشرو عات البحثية المتعددة الأطر اف، والتعاون مع المؤسسات البحثية الأخرى وقطاع الصناعات الدوائية. لتمثلهم في إدارة النشاط و الحياة الجامعية.

دعم الدر اسات العليا والبحث العلمي بأقسام الكلية وذلك بتطوير البرامج الدراسية والخطط البحثيـة وتشجيع المشـاركة في المشرو عات البحثيـة المتعددة الأطر اف و التعـاون مـع المؤسسـات البحثيـة الأخرى وقطـاع الصناعات الدوائيـة. و إعداد وتدريب الكو ادر العلميـة من أعضاء هيئة التدريس للقيام بمهامهم التعليمية والبحثية و الاستشارية.

2 - 2 - المشاركة المرتبطة بالايمقراطية

ظهرت بعد المشـاركة في تنفيذ الأنشطة والحملات التوعية ضد التدخين والتي استهدفت فئة " الثباب "، لتو عيتهم بأضرار التدخين، و مخاطرة على الصحة. و اتضحت من خلال مشـاركة الطلبة في حملة التوعية ضد مرض السكر للعشو ائيات. وظهرتـا المشـاركة من خـلال الاهتمـام بالمشـاركة المجتمعية لجامعة فاروس؛ وذلك بإمداد مؤسسـات المجتمع بـالخبر اء وتقديم الخدمات المهنية وتتفيذ بر امج متخصصة لتطوير الأداء المهني المستمر، حيث تعد من الصـلاحيات الوظيفية للجامعات ومن الركائز الأساسية التي تدعمها الجامعات الديمقر اطية، بالإضافة للاحتر ام مشاركة الطلبة في جميع الأنشطة ودعهم. وتتضح الايمقراطية من خلال عملية التطوير والتحديث المستمر لبرامج ومناهج مرحلتي البكالوريوس والدراسات العليا لمو اكبة التطور المتسار ع في مجال العلوم الصيدلية و الوصول إلى الاعتماد. 3 - التعليم المبني على خدمة المجتمع ظهر اهتمام الكلية بالتعليم المبني على خدمة المجتمع من خلال البيانات المتاحة

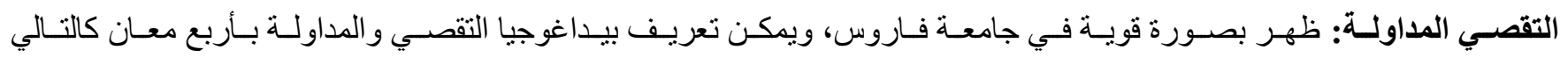
( التعاوني/ التكافلي، حل المشاكل، التفكير النقدي، النقاش والمنـاظرات) ويمكن توضيح التعلم التعاوني هو التعلم القائم على أسـاس المشاركة الفعالة. [54] ويتضح من المهام الأساسية التي تضطلع بها المؤسسة الجامعية؛ فالطلبة وهيئة التدريس و الإدارة مكونات ثلاثة استحدثت لتحقيق هذ الغرض. ومن هذا المنطلق فإن سيطرت الأهداف البيداغوجيا و إنجاح العملية التعليمية يعدان شرطين أساسين، مر هونين بـالحيز المكاني المتمثل بالجامعـة وباستعمالاتها المختلفة، دون أن ينفصل عن السياق المديني و الحضـري. وللتقصسي صيغ بيذاغوجيـة متعددة الأسماء منها على سبيل المثال: التعلم المبني على التقصي (inquiry-based Learning-IBL ) أو التعليم المبني على المشكلات(problem-based Learning- PBL) و التعليم الموجه عن طريق التقصي) - inquiry-guided Learning 


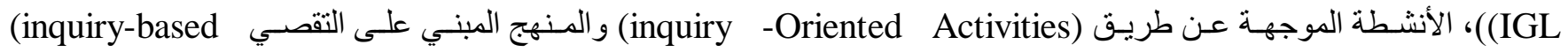
و و النقطة الرئيسية في بيداغوجيا التقصي أن الجواب على أي سؤ ال يحصل استنادا إلى تقصي الوقائع و الوثائق و المراجع ومصادر المعلومات، وثمة أسئلة جديدة يولدها التقصي. ويرنبط بالتقصي مفهوم المذاكرة أو المداولة (deliberation) ، حيث يتم البحث عن الأجوبة وكيفية اتخاذ القرارات، عن طريق النقاش بين المعنيين ينضم إلى الطرق المحفزة على المداولة.

وتستعمل كلمة "بيداغوجيا" للمشاركين وتحمليه. وهي كلمة من أصل يوناني، تتألف من كلمتين، بدوس أبي طفل، وغوجيا: تعني قيادة بذلك يدل هذا المفهوم على الطريقة التي نقود بها أطفالنا ويرتبط بالتقصي بمفهوم المداولة أو المذاكرة حيث يتم البحث عن الأجوبة وكيفية اتخاذ القرار ات، عن طريق النقاش بين المعنيين، في الصف أو في المؤسسة. ومن هذه الزاوية ينضم التعليم التعاوني إلى

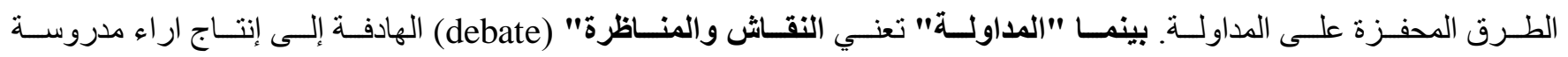
ومستنيرة(informed opinions) حيث تكون في نيـة المشـاركين مر اجعة آر ائهم وتحمل الأفر اد مسئولياتهم كمو اطنين. [55] وتثير الباحثة للتعليم التعاوني بأنه أسلوبا تربويا يطور أجيالا من التعليم لمتبادل ويمثل التفاعل والتعلم والنقاش، فضـلً عن مهام المجموعات و مشارع بحثية مشتركة. و اشارت جامعة فاروس للتعلم المتكافئ بالإجر اءات المتبعة في المجمو عات التي تحدث بشكل منظم ومتسلسل لحل مشكلة معدة مسبقاً، ليكون طلاب الجامعة على وعي بعمليات تفكير النقدي و إدارة هذه العمليات وتقييمها، وهي تعتمد على تخطيط واتخاذ القرار الصائب وحل المشاكل بطريقة علمية.

\section{وأظهرت نتائج البحث الآتي}

اتضح من خـلال اتخـاذ القراءات التعليميـة المتعلقة بالجامعة من تنظيم قو افل بحوث ودر اسـات للحسالات للعزب الفقيرة (عزبـة الجـامع و عزبة سكينة وقافلة نوزيع شنط الخير بعزبة فتى وبعزبة الجامع)، حيث نظمت الجامعة بالتنسيق مـ كليـة الصيدلة و التصنيع الدوائي حملة تبر عات عينية الباطنين. وأضحت نتائج تحليل البيانات الجاهزة لموقع الكلية أن الكلية تهتم بالمناطق العشو ائية وذلك توثيقًا لدور الجامعة في تتمية المجتمع. والتي نظمت فيها جامعة فاروس بالتنسيق مع كلية الصيدلة والتصنيع الدوائي وكلية العلاج الطبيعي حمالات التبرع بالدم في النوادي.

وفي ضـوء تعزيز العلاقـات و التعـاون المتبـادل بين جامعة فـاروس، وسفارة جمهوريـة الصين الثـعبية قامت عميدة [56] العلاقـات الخارجية، وضمان الجودة بالجامعة بزيارة القتصلية الصينية بالإسكندرية لحضور ندوة موسيقية. يتم اتباع أسلوب النقاش والمنـاظرة في الجلسات الحوارية وأثناء عقد السيمنار ات العلمية التي يكتسب الطلاب منها القدرة على التقيم النقدي للمعلومات وتدوينها، لتحسين أبحاثهم والمحافظة على الوعي الايجابي النقاش، وتقبل الر أي الأخر و اكتسابهم ثقافة التفاعلية. 
4 - المواطنة : ظهرت بوضوح من خـلال الانخر اط في الحيـاة العامـة لإدارة الأنشطة الطلابيـة بالجامعـة، وتنفيذ احتفاليـة بيوم اليتيم الخامس، وقد شارك فيها أكثر من 320 طفل ينتمون للجمعيات الخيرية بحضور طلاب الجامعة.

5 - التعليم المبني على خدمة المجتمع

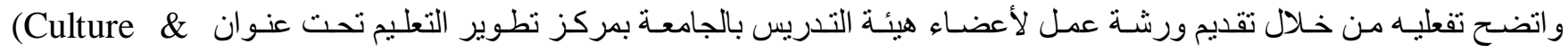
بeadership). الأسنان. ويهدف المؤتمر إلى نقل وتشجيع المعرفة والقيام بالأبحاث العلميـة في ظل التحولات المجتمعية الر اهنـة ووقعت فعاليات التي تخدم منظمات المجتمع.[57] في ضوء التعاون المستمر ما بين جامعة فاروس بالإسكندرية وسفارة دولة السويد بالقاهرة، و المعهد الملكي للتكنولوجيا بالسويد، قامت إدارة العلاقات الدولية بالتعاون مع كلية الهندسة بجامعـة فاروس بإقامـة اليوم السويدي بالجامعـة، وفى إطـار التعاون القائم ما بين جامعة فاروس بالإسكندرية و المؤسسات الدولية المختلفة، و التعاون المشترك و المستمر بين جامعة فاروس وجامعة وتر فورد للتكنولوجيا بإيرلندا. [58]

6 - تعليم الانسانيات: ظهرت بقوة من خـلال منافسـة الجامعتين لتكوين شر اكات من أجل كسب الربح والعائد الاقتصـادي، نقل الخبرة بين الجامعات من خلال اشتر الك الطلاب في المؤتمرات الدولية وتقديم الأبحاث. و اتضح ذللك في ضوء نقل الخبرات وتعليم الانسـيات فقد قامت جامعة فاروس بالآتي أقامت المعرض الروسي ضم مجموعة كبيرة من أعمال طلاب الفرقة الإعدادية لمقرر دراسات من المتاحف وضم المعرض أيضا مجمو عة من الصور الفوتوغر افية للطلاب.

المحور الخامس: نتائج البحث ومناقشتها أولًا: النتائج النظرية للبحث ودلالاتها في ضوء التصور النظري للبحثــ و الذي اعتمد على نظريـة التنميـة المستدامة، وأهم القضـايا النظريـة المستخلصـة منها بالإضـافة إلى دمج نتائج تحليل أدلة المقابلات الفردية لوكلاء خدمة المجتمع وتنمية البيئة في الجامعتين.[59] نتائج البحث في ضوء القضايا النظرية التي يطرحها البحث الراهن أ ـ التنمية المستدامة تضمن عملية تعزيز ثقافة المواطنين بقيم المشاركة والمواطنة

بينت نتائج البحث ضعف الوعي المجتمعي بأهمية المشاركة الاجتماعية في مجالات تتمية خدمة المجتمع والدور التنموي، حيث أوضحت وجود بعض القيود الاجتماعية التي تؤثر على المشاركة الفاعلة في التنمية. 
تؤكد هذه النتيجة إحدى القضايا التي يطرحها منظور التنمية البشرية المستدامة، حيث ترى أن المجتمع لا يتقدم إلا إذا تخلص من القيود التي يفرضها المجتمع، وتمكين المشـاركة للجامعة وقدرتها على الوصول إلى فرص منكافئة في كل المجالات، ممـا يسرع من عملية تمكينها ويفعل مشاركتها في التتمية. و اتضح أن وظائف الجامعة لا تقتصر على تعليم الطلاب والبحث العلمي فقط، و إنما تقوم بالعديد من الوظائف الأخرى ومنها خدمة المجتمع .و أثنتت نتائج البحث أن جامعة الاسكندرية تواجه العديد من المشاكل التي تو اجه المجمع، وتعوق تنمية مجتمعاتها، ومن أهم هذه المشكلات ( البطالة ـ الأمية ـ الأعداد المتز ايدة للارسين - وقلة الموارد المادية). ب ـ أكدت نتائج البحث أن محور اهتمام الجامعة هو نشر العلم والثقافة، ولا يقتصر على طلابها فقط، بل يشمل ذلك كل المواطنين الموجودين المجتمع المحلي. وتوصلت نتائج البحث إلى عدد من النتائج العامة و التي يتم تفسير ها في ضو ء القضايا النظرية التي تتطلق منها التنميـة المستدامة، وقد أوضحت نتائج البحث أن بعد المشاركة وتحمل الأفر اد والمؤسسات المسؤولة تجاه المجتمع وفرضته قد تحقق، وهذا مـا أظهرته نتائج البحث في الجامعتين من إحداث بر امج مشاركة الطلبة في الأنشطة المجتمعية، وأنشطه المسئولية المدنية للجامعتين، وظهر من خلال المشاركة في المؤتمرات والقيام بالأبحاث العلمية قضية التنمية المستدامة التي ترتكز على عملية التعليم وتنمية المجتمع. أثثتت نتائج البحث لا يمكن الاعتماد على التنمية المستدامة بدون الاعتمـاد على التعليم ونوضيح الرؤيـة الاستر اتيجية للمؤسسـة الجامعة، فالجامعتين تدعيم أبعاد المسئولية المدنية واتضح ذلك من خلال تفعيل مؤشرات التنمية المستدامة القائمة على فاعلية العلاقات بين الطلاب و الهيئة التعليمية و الأساتذة بصورة فردية أو جماعية و المشاركة في العمل التطوعي مثثل الندوات والأنشطة المجتمعية المتنوعة لخدمـة المجتمع وتنميته ـكما أثتبت النتائج مدى التز ام الجامعتين بتفعيل قيم المشاركة والحريـة الاكاديميـة والمو اطنـة وخدمـة المجتمع القائم على تعليم البيئي، فلا يمكن أن تحدث التنميـة المستدامة في الجامعتين (الإسكندرية وفاروس) بدون الاعتمـاد على إشر الك العاملين بالجامعة ومشاركتهم في تتفعل الرؤية الاستراتيجية للكليات وللجامعة وذللك لتوفير الجامعة بعض الامكانيات وتعزيز الحوار مع المسؤولين لتحقيق أهدافها. وكذلك أوضحت مدى وجود دمج للمسئولية المدنية والاجتماعية في الخطط الاستر اتيجية المرتبطة بخدمة المجتمع وتنمية البيئة.

\section{ثانيًا: في ضوء المفاهيم النظرية للبحث}

1 - التنمية البشرية المستدامة يقصد بها الاستمرار و التو اصل من خلال تمكين القدرات التي تم تتميتها، وتعزيز الخيارات البشرية من الفرد و المشاركة في صنع القرار. [60]وتهدف لتوفير الرفاهية الاقتصادية للأجيال القادمة لضمان المستقبل، وحفظ نظم دعم الحياة التي توفرها للأجيال القادمة [61] أثتتت نتائج البحث الميدانية أن هناك تمكين للطلاب ويتضح من خلال المشـاركة في المؤتمرات والندو ات وملتقي التوظيف الذي يؤكد على المشاركة المجتمعية بين الجامعتين ومؤسسات المجتمع المدني المهتمة بخدمة المجتمع. 
2 - المواطنة: ظهرت بصورة واضحة للجامعتين من حيث انخر اط الطلبة في الأنشطة البيئة والترفيهية للجامعتين. أمسا مو اطنة الجامعتين، حيث رصدت نتائج البحث مدى تفوق جامعة فاروس في الجانب التطبيقي، والأبحاث الميدانيـة الثهرية نظر آ لمـا تتمتع بـه من أمكانيات عن جامعة الاسكندرية .

مفهوم خدمة المجتمع: اتضح أن هناك علاقة واثقة بين الجامعـة والبيئة المحيطة وخاصـة المناطق العشو ائية وتمثلت تلك الخدمة في تنفيذ بر امج خدمة المجتمع مثل بر امج: (محو الأمية وقو افل طيبة وحمالات توعيـة وتبرع بالدم، والاحتفالات بيوم اليتم وفتح العيادات الخارجية مجانًا لرغبي الخدمة .إلخ) تبين الارتباط القوي بين المواطنـة وخدمة المجتمع، و أظهرت النتائج تفعيل بعد المسئولية المدنية و هو " خدمة المجتمع بتنفيذ بعض الأنشطة الجامعية، و الإشر اف مع إدارة العملية التعليمية ببرنامج التعليم المفتوح الخاص بكلية التجارة دور ها الو اضح لعملية التشغيل والتدريس. وأثنتت النتائج أن كلية العلوم الإدارية والمالية بجامعة فاروس لديها العديد من تفعيل وتطبيق بعد خدمة المجتمع وتتميته على الرغم من عدم وجود قطاع خدمة المجتمع وتنمية البيئة إلا أن الكلية تقوم بتفعيل خدمة المجتمع.[62] 3 - الديمقراطية: تحقق هذا المفهوم كمشاركة تطو عية للجامعتين و التي ظهرت من حيث الاهتمام الفعال بالأنشطة المجتمعية التي يقوم بها الطلبة. وتبين مدى الاختلاف الو اضح بين مواطنة الجـامعتين وأتضـح ذلك من خلال الاطلاع على البيانات الجـاهزة و العرض السـابق، نظرًا لتفوق جامعة فاروس في الإمكانيات المتاحة والتي تسـاعدها على التنافس ومو اكبـة التطوير التكنولوجي من حيث مشـاركة الطلبـة بالأبحاث الاكاديمية التي تخدم المجتمع. 4 - التقصي والمداولة مجمو عة الوسائل المستعملة لتحقيق التربية، والأسلوب أو النظام الذي يتبع في تكوين الفرد [63] وبينت نتائج البحث الاختلاف الو اضح بين الجامعتين حيث تحتل جامعة فاروس المكانة الأعلى في تطبيق الجانب التطبيقي والتركيز على المناقتـة والحوار في المحاضر ات نظرًا لما تتمتع به من قلة الأعداد الطلبة.

5 - ثقافة القانون: تعنـي فحص الخطاب يقصد بـالخطـاب، النصــوص التوجيهيـة التـي تصــدر عـن الجـامـــة، والتـي تعكس عمليا فلسفتها وقيمها. و هذه النصوص على نوعين - : النوع الأول، نصوص عامـة، كالرؤيـة و الرسـالة والقيم و المبادئ الموجهة، والتوجهات الاستر اتيجية... إلخ. وقد تم البحث عن هذه النصوص على أربعة مستويات: مستوى الجامعة

ثقافة القانون في الجامعات العربية كمؤسسة مستوى الكلية والمعهد؛ مستوى القسم؛ ومستوى الوحدة غير التعليمية بينما النـوع الثاني، نصسوص صـادرة عن قيـادات الجامعة (رئيس الجـامعـة، عميد الكلية، رئيس القسم، مدير مركز. إلخ) بصورة رسـالة أو كلمـة، عادة ما يتم توجيهها إلى الجمهور في مطلع السنة الدراسية أو في مناسبات معينة. 
ونبين أدناه الصيغ والأثكال التي وجدناها لكل من هذه المعاني الثلاثة تساوي الجامعتين في تطبيق ثقافة القانون، وظهرت بصورة واضحة في القو اعد المتابعة في الجامعتين من احترام حقوق الإنسان.[64]

أظهرت وجود اختلاف في تطبيق وتفعيل الحرية الاكاديمية في الجامعة، واتضح ذلك من خلال العلاقة بين الجامعة والمجتمع ونلاحظ تفوق جامعة فاروس عن جامعة الاسكندرية من الجانب التطبيقي والاهتمام بالأبحاث العلمية. التي تضمن حرية السادة الاساتذة وأعضاء هيئة التدريس فيمـا يتعلق بالقضـايا ومناقشتها داخل محاضـرات قاعـات الجامعـة بالاستناد إلى معايير الجودة المعتمدة بهدف تحديد

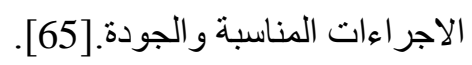

في ضوء أهداف وتساؤلات البحث توصل البحث فيما يتعلق بالهدف الأول: وهو التعرف على أبعاد المسئولية المدنية للجامعات حقق البحث هذا الهذف حيث توصل البحث للنتائج التالية

أثنتت تحقق بعد المسئولية الددنية للجامعتين بتنفيذ أنثطة كليات المجتمع الدراسي وتحقيق أوجه المشاركة المجتمعية للكليات من حيث تنظيم يوم بيئي بكليات الجامعتين ومثاركة الطلاب في حمله تنظيف وتجميل الكلية والمدينة الجامعية. و أثنتت النتائج عقد الجامعة ملتقي التوظيف السنوي و الذي يهدف الاستضافة للثركات و الدو ائية. [66 ] أن هناك تنظيم حملات تبرع بالدم من الطلاب في جامعة فاروس أكبر، وذلك لتوفير الامكانيات المادية ولتوفير الدم اللازم للمرضى في بنك الدم لخدمة المرضى والمصابين (64) مقابلة مجدي خليل ،2015/12/19)، و هذا من وقع تحليل البيانات الجاهزة و الاطلاع عليها. ومن ثم توسيع الخبار ات المتاحة أمامهم من أجل تحسين الاداء و القضاء على الفقر.

(أما عن الهدف الثاني: رصد دور الجامعات في خدمة المجتمع وتتمية ( الإسكندرية، وفاروس) أثنتت نتائج البحث مدي مساهمة الجامعتين في تتمية المجتمع المحيط، وخدمة مجتمعه. و أوضحت النتائج أن هناك تفعيل لدور خدمة المجتمع من خلال تمكين الطلاب من الاشتراك في الندوات والدورات التي تعقدها الكليات و الثركات داخل وخارج الجامعتين. ودعم قدرتهم على المشاركة بفاعلية في الانثطة الاجتماعية و العمل على تحقيق التنمية المستدامة للجامعة في إطار تتفيذ برنامج الكلية لتنتجيع ثقافة البحث و التطوير لدى الطلاب. 
والهـف الثالث: رصد التحديات والمعوقات التي تواجه الجـامعتين في تفعيل وتطبيق المسئولية المدنية والدور المدني للجامعات المصرية: تم الإجابة على التساؤلات المتعلقة بالتحديات التي تواجه الجامعتين في تحقيق أهدافها، وأتضح تنوع هذه المعوقات واختلافها بين الجامعتين( الإسكندرية وفاروس ) نقص التدريب الخـاص لطلاب جامعة الإسكندرية من حيث التوجها إلى تخصصـات علميـة غير مطلوبـة في سوق العمل، عدم توفير قاعات مجهزة للجامعة على عكس جامعة فاروس. و أكدت على وجود تحديات اجتماعية نواجها الجامعتين، مثل اختلاف ثقافة المجتمع، و عدم اقتناع الطلاب بثقافة العمل الحر والتطوعي في المجالات التي تخدم المجنمع. حيث أنه بـالرغم من أن الطلاب يقومون بأبحاث اجنماعيـة تخدم المجتمع، الإ أن تلك الأبحاث تعد إجباريـة من قبل الجامعة، وقلة الإمكانيات الماديـة والماليـة المتمثلة في ضـف حجم الإنفاق على الأبحاث في الجامعة، مما يعتبر معوقُّا لأنشطة البحث في جامعة الإسكندرية، خاصـة في الابحـاث العلمية المرتبطة بكلية صيدلة اسكندرية بصفة خاصة.

كمـا أكدت أحدى حـالات المقابلات "أفر اد عينـة البحث"، أن هنـالك كثيرا من العـاملين بمصـانع الأدويـة يرون أن مهـة وحد الأبحـاث و الرقابة ليست تطوير منتجات جديدة وإنما مجرد إجر اء الأبحاث المتعلقة برقابة المنتج و إجر اء التعديلات الطفيفة لزيادة فعاليته بالاعتمـاد على مو اد بديلة أقل تكلفة .

فيما يتطلق بالهـف الرابع: وهو التعرف على آليات تفعيل المسئولية المدنية للجامعات المصرية ( الإسكندرية وفاروس) ويتضح مما سبق ذكره العمل على إز الة التحديات التي تواجه الجامعة والتي ظهرت فيما يلي التنسيق والتعاون بين كل كليات جامعة فروس في تنفيذ أنشطة تتمية البيئة خدمة المجتمع. و الاهتمـام بأبعاد المسئولية المدنيـة للجامعـة. وأوضحت نتائج البحث عدم وجود هيئة معاونـة لوكيل الكلية لشئون خدمة المجتمع وتتمية البيئة منذ عام 2015.

أنثتت النتائج الميدانية للبحث غياب عقود وبروتكو لات الثر اكة المجتمعية بين شركات تصنيع الدواء بالإسكندرية والجامعة، حيث يوجد بالجامعة كلية الصيدلية و التصنيع الدو ائي. على الرغم من أن المهمة الأساسية لإدارة العلاقات الدولية بجامعة فاروس و انشـاء وتقويـة رو ابط التعاون مع الجامعات و المعاهد الدولية لتمهيد الطريق نحو، وذلك لإخر اج طلابا وأستاذة وباحثين مؤهلين و قادرين على الابتكار و المنافسة في مختلف المجالات.[67]

كما أثنتت النتائج عدم وجود توقيع برتوكو لات شر اكة بين الجامعتين(الإسكندرية وفاروس) على الرغم من الجامعتين يقعان في محافظة

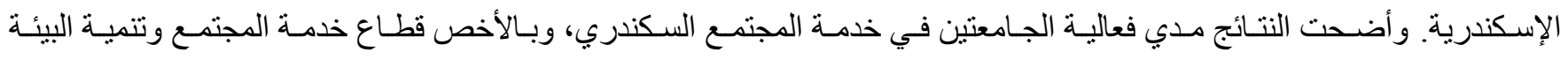


بالجامعتين ( الإسكندرية وفاروس). بينت النتائج ضرورة تفعيل الثقافة القانونية وربطها بثقافة حقوق الإنسان، وأثنتت النتائج قدرة كلية الصيدلة والتصنيع الدو ائي على طرح إجر اءات اللازمة لتوفير الطاقة المتجدة.]68]

ثالثا: الالالات العملية لنتائج البحث

اتضحت من خلال نتائج البحث الر اهن حول: "و اقع المسئولية المدنية للجامعتين في تتميـة المجتمع المحلي، ويمكن صياغة الدلالات العملية في مجموعة من التوصيات مقسمة إلى عدة محساور تخاطب جهات تشريعية وتنفيذيـة مختلفة ( الجامعـات، المجتمع المدني، الدولة). ويمكن توضيحها فيما يلي:

يجب تطوير الجامعات الحكومية ودعمها ماديًا لتحصل على أعتاد الجودة بمـا يتيح لها القدرة على المنافسـة مـع جامعة فاروس الخاصـة وتحتل مركز وفقاً للتصنيف الجامعـات. أمـا بالنسبة للكليـات العلميـة فيجب تطوير المعامـل بجامعـة الاسكندرية بشكل يجعلهـا جاذبـة للقطاعات الإنتاجية بما يتناسب مع معايير الجودة، وبما يتناسب مع تنفيذ الابحاث.

ضرورة تخفيف الأعباء التي يعاني منها أعضـاء هيئة التدريس والتي رصدتها نتائج البحث الميداني لجامعة فاروس، والتأكيد على مـا نص عليه قانون تتظيم الجامعات بضرورة عضوية مجالس الكلية من ذوي الخبرة بمؤسسـات الانتاج، لمـا لـه من أثر إيجابي في فتح قنوات للاتصـال مـع المجتمع، ضـرورة تفعيل محتويـات المـواد التـي يتلقاهـا طلبـة جامعـة الإسكندرية ( الكليـات النظريـة و العمليـة) مـع الأنشطة التي تتم عن مثلماً يتم في جامعة فاروس.

2 ـ المجتمع المدني: تمكّن الجامعـة وتعاونهـا مـع المجتمـع المـنـي: من الاضطلاع بوظيفتها وتحمّل مسئولياتها تجـاه المجتمع وضمان موضو عية المعرفة وصر امة التعليم والبحث.

3 - الدولـة: ضـرورة الاهتمـام بالبحـث العلمـي ورفع ميز انيتهـهـ مـن أجـل إجـراء بحـوث تطبيقيـة مهمـة لخدمـة المجتمـع المحلـي، وإصـدار بروتكو لات تعاون الجامعة مع الجهات الحكومية بالدولة للربط و إجر اء الابحاث التطبيقية الصناعية لخدمة المجتمع أيضـا. ربط المبدعين و البـاحثين مـع صناع القر ار والسياسـات بالجهات الحكوميـة لدر اسـة مقترحات السياسـة العامـة التي تتم عن طريق إعداد وتنفيذ بر امج التدريب لقطاع خدمة المجتمع بالجامعة. 
[1] Rajesh Tandon, Budd Hall. UNESCO Chair on Community Based Research \& Social Responsibility in Higher Education: A Framework for Action. University of Victoria,NewDelhi; 2012-2016. http://www.livingknowledge.org/livingknowledge/wpcontent/uploads/2012/09/UNESCO-Chair-onFramework-for-action.pdf

[2] محي زيتون. إنكالية التنمية في مصر بين ميراث الليبر الية الجديدة وتطلعات مجتمع المعرفة. بيروت، مؤسسة الفكر العربي؛ ابريل 2013. [3] الد خميس السحاتي. الدور المدني للجامعات قر اعة أولية في الادبيات. برلينـ ألمانيا: المركز الديمقر اطي العربي للار اسات

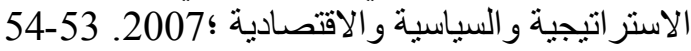

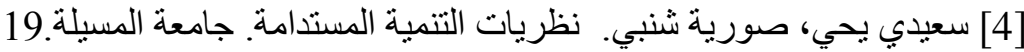

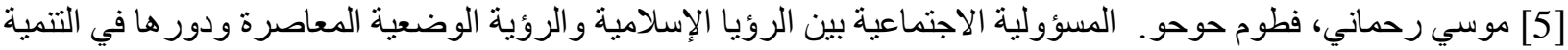

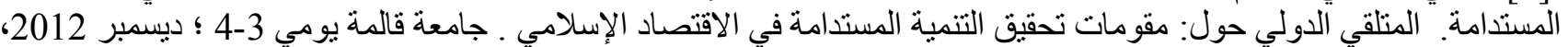
جامعة بسكرة

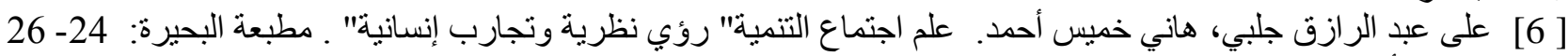

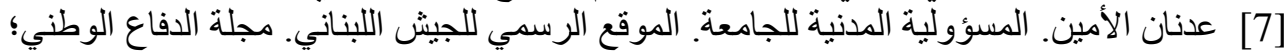

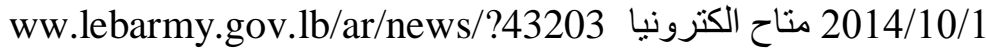

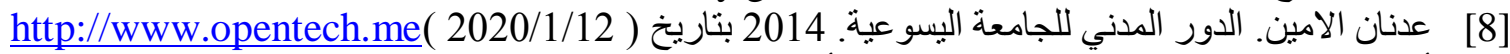

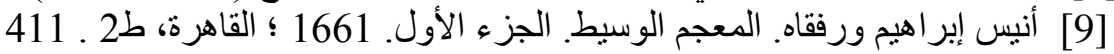

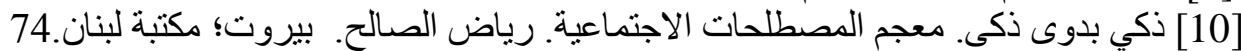

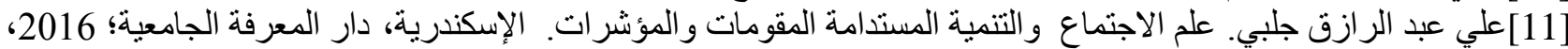
ص27 ص

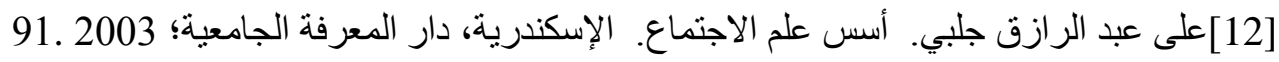
[13] Newman ‘1, Basics of Social Research : Qualative Approches New yark, person Education, I nc, 2004, p, 308

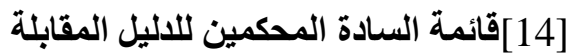

1 - [14]أ.د / سامية جابر ، أستاذ علم الاجتماع, كلية الآداب, جامعة الإبة الإسكندرية.

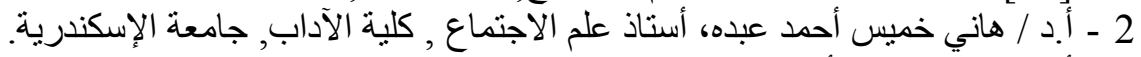

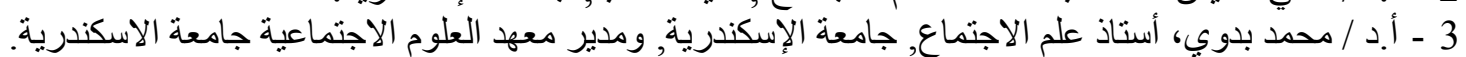

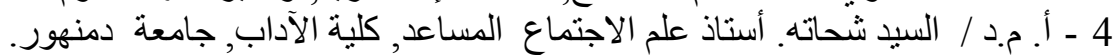

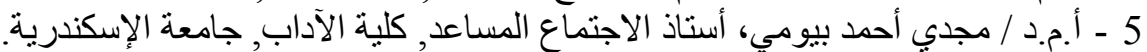

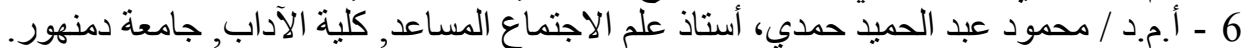

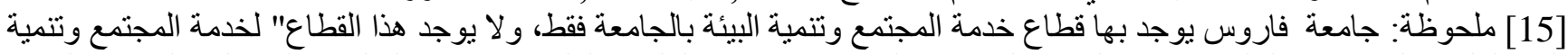

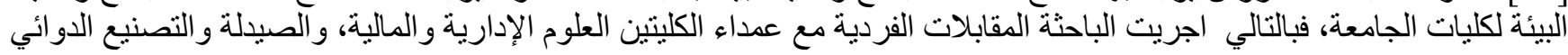
بجامعة فاروس.

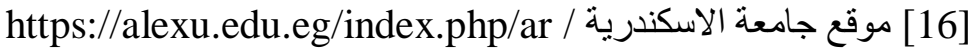

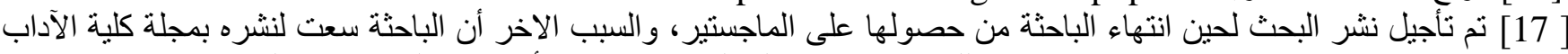

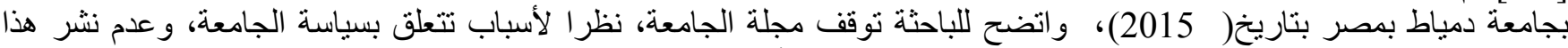
البحث بالمجلة، ولهذا السبب كان هنالك دافع قوي للسعي الباحثة مرة أخري. للبح

[18 ] Thornton, Courtney H, Civic responsibility and research universities: Ideology, culture and action, North Carolina State University, Ed.D., United States, Ann Arbor , ProQuest, http://search.proquest.com/docview/305294290?accountid=37552 (12/12/2015)

[19] زياد بركات أحمد عوض. و واقع دور الجامعات العربية في تنمية مجتمع المعرفة من وجهة تطوعية من أعضاء هيئة التدريس http://www.qou.edu5) فيها. 2011 ناريخ الدخول (

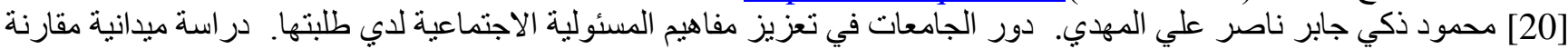
بين جامعتي حلوان وجامعة الأز هر ، عزة (فلسطين)؛ 2011م 
[21] محمد محمود ولد محمد عيسي. اليات تحسين أداء الجامعات العربية في التصنيفات العالمية. كلية العلوم الاقتصادية والتجارية و علوم التسبير، جامعة عبد الحميد بن باديس، الجز ائر ؛ 2015

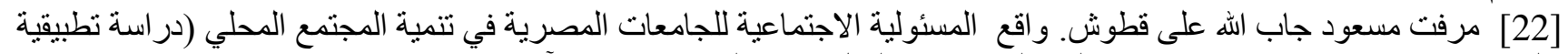

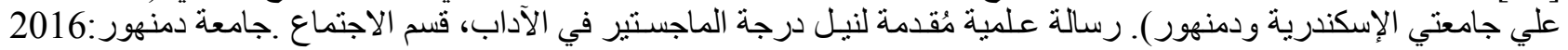

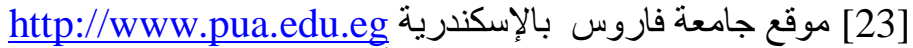

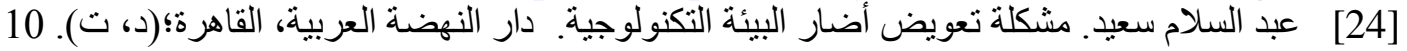
[31] Aspen Institute on June 29- July 1, 1999, http://www.compact.org/resources-forpresidents/presidents- declarationon-the-civic-responsibility-of-higher-education [26] Margaret S Adapted from Branson,. (1998). The Role of Civic Education: A Forthcoming Education Policy Task Force Position Paper from the Communitarian Network, Washington, DC:

Center for Civic s

[27] http://www.civiced.org/articles_role.html

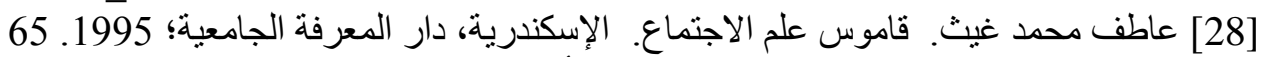

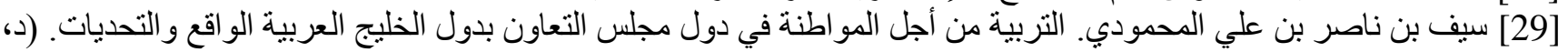

[30] عصمت حسن العقيل، حسن أحمد الحياري. دور الجامعات الأردنية في تدعيم قيم المواطنة. المجلة الأردنية في العلوم

517 : التربوية.2014؛ 10 (4)

[31] Michalis Kakos , Four questions from England about the compatibility of citizenship education to modern schooling ,School of Education, University of Leicester,p,357:356

jhvhttps://lra.le.ac.uk/bitstream/2381/10980/7/4\%20questions\%2030-4pdf

[32] طارق عبد الرؤف محمد عامر. تصور مقترح لتطوير دور الجامعة في خدمة المجتم في ضوء الاتجاهات العالمية الحديثة:

[33] http://www.honors.ufl.edu/Research.as

[34] http://www.depaul.edu/admission-and-aid/Pages

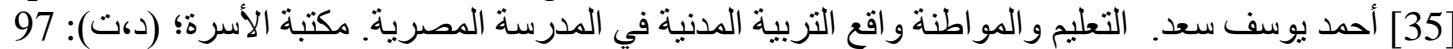

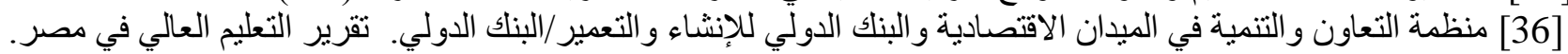

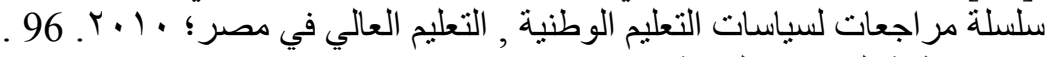

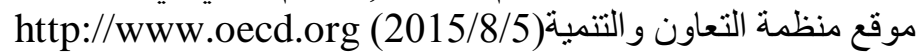

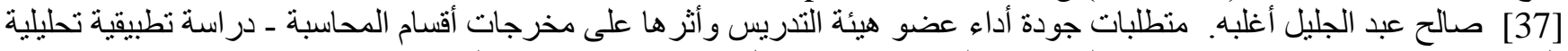

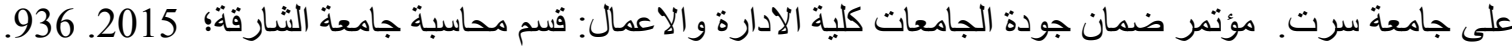

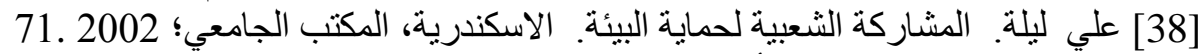

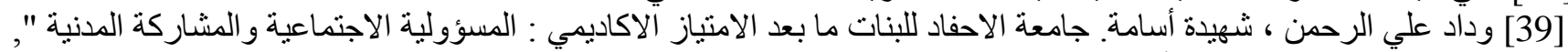

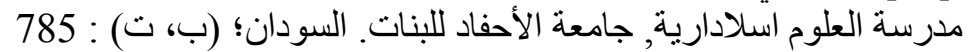
[40] إعلان تايلوا. الدور المدني و المسئولية الاجتماعية للتعليم العالي. متاح الكترونيًا بتاريخ الدخول( 2015/12/5) http://talloiresnetwork.tufts.edu/wp-content/uploads/TalloiresDeclarationinArabic.doc

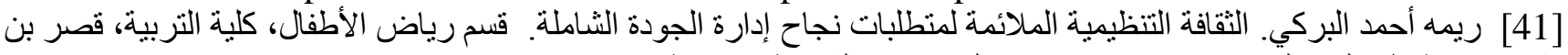

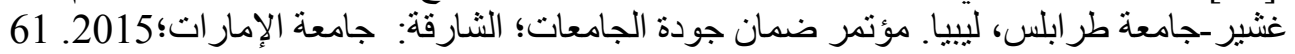

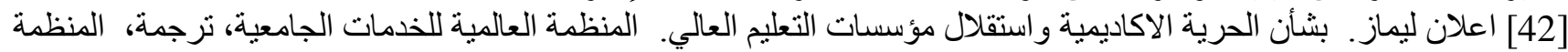

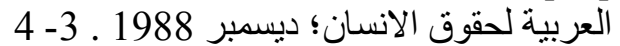

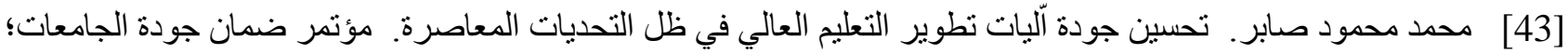

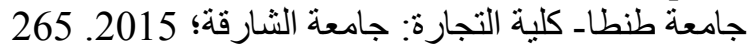

[44] مجلة جامعة فاروس ـ تقرير خدمة المجتمع وتنمية البيئة . العدد الأول ؛ مخصصة معتمدة: بالاسكندرية؛2014. 23 https://www.pua.edu.eg

https://www.pua.edu.eg [45] اللائحة الداخلية للكلية العلوم المالية و الادارية, 2015 [46]World Conference on Higher Education.The New Dynamics of Higher Education and Research For Societal Change and Development. 2009 
[47] خالد كاظم أبو دوح. علم الاجتماع السياسي و المعاصر و التطور ات المعاصرة وتطبيقات على الاحتجاج و الثورة في المجتمع العربي. القاهرة.

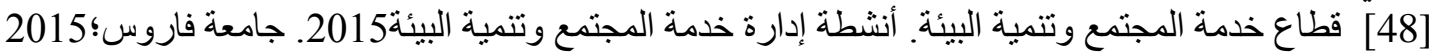

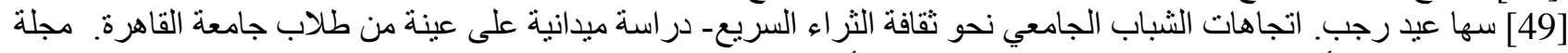

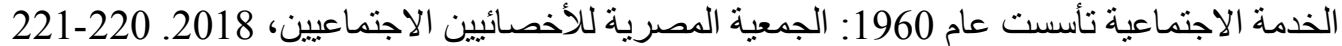

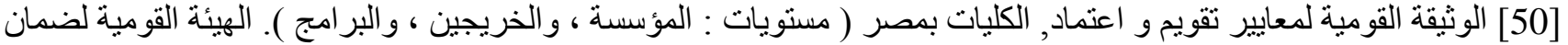

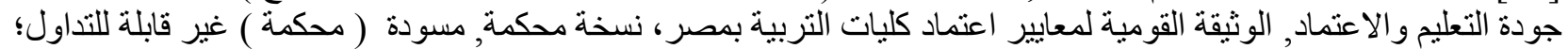

$37: 36.2010$

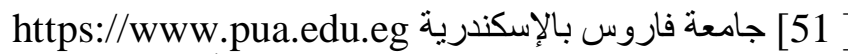

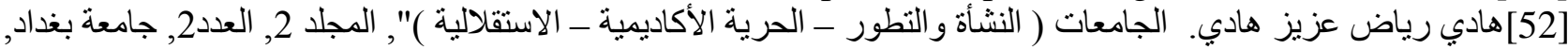

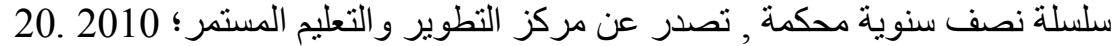
[ 53] علاء عدنان عباس. دور الحرية الأكاديمية والديمقر اطية التربوية في تطوير مناهج التعليم الأكاديمي (جامعات حكومية- جامعة

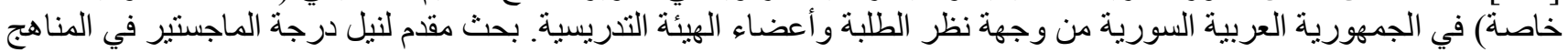

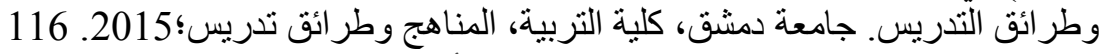

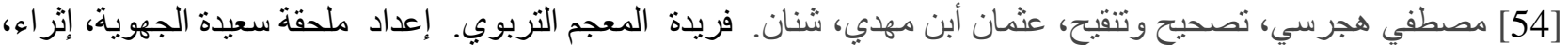
الجمهورية الجزائرية الديمقراطية العبية، وزارة الثقافة، المركز الوطني للوثائق التربوية. https://slpemad.files.wordpress.com

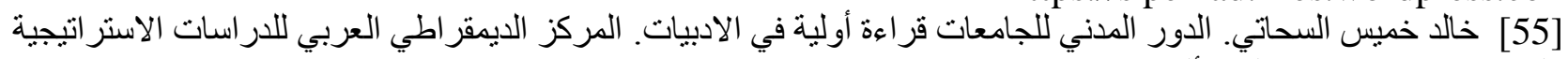

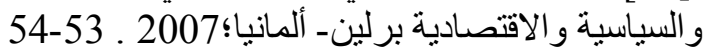
][56 الأستاذة الدكتورة ماجدة المسيك عميدة العلاقات الخارجية العانية.

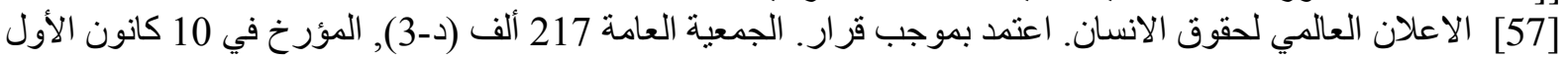

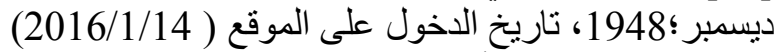
WWW.pua.edu.eg [58 ] جامعة فاروس. أنشطة إدارة خدمة المجتمع وتنمية البيئة. جامعة فاروس؛ [59] المقابلات الفردية لوكلاء خدمة المجتمع وتنمية البيئة في الجامعتين الجئة

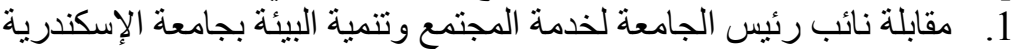

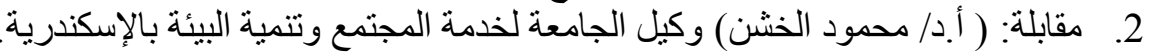

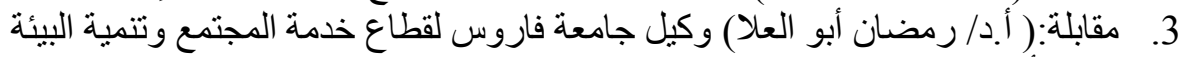

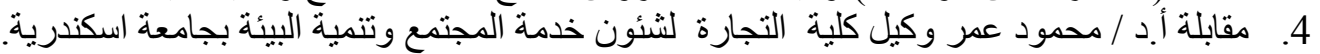

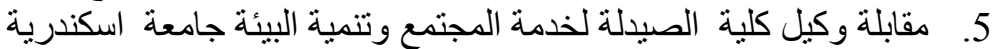

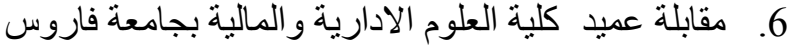
7.

[60] منظمة العمل الدولية. تقرير جديد لمنظمة العمل الدولية حول اتجاهات الاستخدام العالمية. بيروت، المكتب الاقليمي للاول

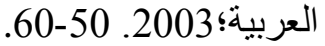

[61] نوز اد عبد الرحمن الهيتي. التنمية المستدامة الإطار العام والتطبيقات دولة الإمار ات العربية المتحدة نموذجا. أبو ظبى, مركز الإمار ات للار اسات و البحوث الإستر الإنتر اتيجية؛

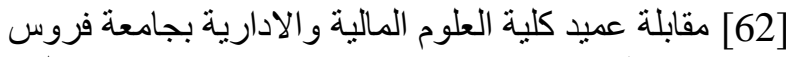

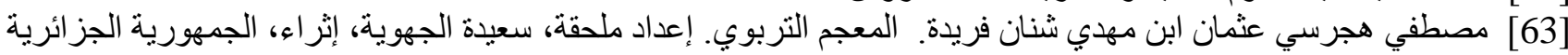
الديمقراطية العبية. وزارة الثقافة، المركز الوطني للوثائق التربوية؛ 2009. 201، 101.

[64] عدنان الأمين ـ ثقافة القانون في الجامعات العربية. مجلة إضافات العددان، 36-37 خريفة2016شتاء 2017 2017. 76- 7 http://www.laes.org/upload/editor_upload/file

[65] مقابلة أ.د/ رمضان أبو العلا- وكيل جامعة فاروس لقطاع خدمة المجتمع وتتمية البيئة.

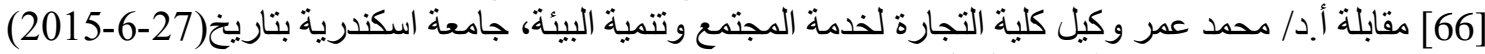

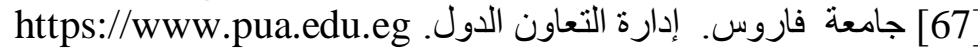

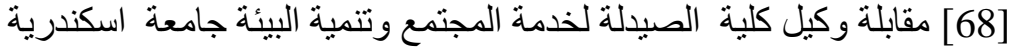

